\title{
Endothelial Protein C Receptor Could Contribute to Experimental Malaria-Associated Acute Respiratory Distress Syndrome
}

\author{
Luana dos Santos Ortolan $\mathbb{D}^{1},{ }^{1}$ Michelle Klein Sercundes, ${ }^{2}$ Gabriel Candido Moura, ${ }^{2}$ \\ Thatyane de Castro Quirino, ${ }^{2}$ Daniela Debone, ${ }^{2}$ Douglas de Sousa Costa, ${ }^{3}$ Oscar Murillo $\left(\mathbb{D},{ }^{3}\right.$ \\ Claudio Romero Farias Marinho $\mathbb{D}^{3}{ }^{3}$ and Sabrina Epiphanio $\mathbb{D}^{1,2}$ \\ ${ }^{1}$ Department of Immunology, Biomedical Science Institute, University of São Paulo (USP), 1730 Professor Lineu Prestes Avenue, \\ 05508-900 São Paulo, Brazil \\ ${ }^{2}$ Department of Clinical and Toxicological Analyses, Faculty of Pharmaceutical Science, University of São Paulo (USP), 580 Professor \\ Lineu Prestes Avenue, 05508-000 São Paulo, São Paulo, Brazil \\ ${ }^{3}$ Department of Parasitology, Biomedical Science Institute, University of São Paulo (USP), 1374 Professor Lineu Prestes Avenue, \\ 05508-000 São Paulo, São Paulo, Brazil
}

Correspondence should be addressed to Luana dos Santos Ortolan; luana_ortolan@yahoo.com.br and Sabrina Epiphanio; sabrinae@usp.br

Received 13 May 2019; Revised 26 September 2019; Accepted 16 October 2019; Published 4 December 2019

Academic Editor: Ravirajsinh Jadeja

Copyright (C) 2019 Luana dos Santos Ortolan et al. This is an open access article distributed under the Creative Commons Attribution License, which permits unrestricted use, distribution, and reproduction in any medium, provided the original work is properly cited.

\begin{abstract}
The severity of Plasmodium falciparum malaria is associated with parasite cytoadherence, but there is limited knowledge about the effect of parasite cytoadherence in malaria-associated acute respiratory distress syndrome (ARDS). Our objective was to evaluate the cytoadherence of infected red blood cells (iRBCs) in a murine model of ARDS and to appraise a potential function of endothelial protein $\mathrm{C}$ receptor (EPCR) in ARDS pathogenesis. DBA/2 mice infected with P. berghei ANKA were classified as ARDS- or hyperparasitemia- (HP-) developing mice according to respiratory parameters and parasitemia. Lungs, blood, and bronchoalveolar lavage were collected for gene expression or protein analyses. Primary cultures of microvascular lung endothelial cells from DBA/2 mice were analyzed for iRBC interactions. Lungs from ARDS-developing mice showed evidence of iRBC accumulation along with an increase in EPCR and TNF concentrations. Furthermore, TNF increased iRBC adherence in vitro. Dexamethasone-treated infected mice showed low levels of TNF and EPCR mRNA expression and, finally, decreased vascular permeability, thus protecting mice from ARDS. In conclusion, we identified that increased iRBC cytoadherence in the lungs underlies malaria-associated ARDS in DBA/2-infected mice and that inflammation increased cytoadherence capacity, suggesting a participation of EPCR and a conceivable target for drug development.
\end{abstract}

\section{Introduction}

Malaria infection by Plasmodium falciparum is responsible for the largest number of severe and fatal diseases in the tropics $[1,2]$. The main complications of $P$. falciparum infection include cerebral malaria, pulmonary complications, acute renal failure, severe anemia, bleeding, and placental malaria [3]. An important aspect of the pathogenesis of severe malaria results from the ability of infected red blood cells (iRBCs) to adhere to the microvasculature. This interaction between iRBCs and the endothelium can cause blocking of blood flow and/or a local inflammatory response [3-5]. Furthermore, these adhesions promote the disappearance of asexual forms of the parasite in the peripheral circulation, thus preventing them from being destroyed in the spleen $[3,5,6]$. Pulmonary complications caused by severe malaria include acute respiratory distress syndrome (ARDS), which has been associated with not only severe malaria but also different diseases [7-9]. Although malaria-associated ARDS often causes a high mortality rate, not so much research has 
been performed. Murine models have been used to study malaria-associated ARDS $[10,11]$, and DBA/2 mice infected with $P$. berghei ANKA (PbA) develop ARDS and die between the 7 th to 12 th day postinfection (dpi) with pleural effusion, edema, and inflammatory infiltration in the lungs but without signals of cerebral malaria. In contrast, DBA/2 mice that died after the 13th dpi exhibited pale lungs, no pleural effusion, and high levels of parasitemia. The cause of death was attributed to hyperparasitemia (HP) and consequent anemia. In addition, we established predictive criteria to distinguish which mice would die from ARDS on the 7th dpi using respiratory and parasitemia data [12]. Using this model, we found that on average $50 \%$ of the mice died from ARDS and $50 \%$ died from HP. We found that recruitment of neutrophils and vascular endothelial growth factor (VEGF) is essential to the pathogenesis of malaria-associated ARDS [13, 14] and that the induction of heme oxygenase-1 (HO-1) has a protective effect against the development of ARDS in mice [15]. Epiphanio et al. showed that sFLT1- (soluble form of VEGF receptor, known to neutralize excess VEGF in circulation) expressing adenovirus-treated mice protected against ARDS which was correlated with a significant decrease in VEGF levels in circulation, even as carbon monoxide administration by inhalation suppresses the onset of this syndrome [13]. In addition, it was demonstrated that hemin- (inducer of HO-1) treated mice also had reduced VEGF levels and were protected against ARDS, defending the alveolar capillary barrier in vitro [15]. Although VEGF is important in the PbAinfection of DBA/2 mice, this is not a universal effect, since the neutralization of VEGF receptor-2 did not decrease ARDS pathology in $P$. berghei NK65-infected C57BL/6 mice, another well-defined and accepted model of ARDS in malaria [16].

Additionally, it has already been demonstrated that PbA-iRBCs adhere to MVECs (microvascular lung endothelial cells from CBA/Ca mice) and that TNF-stimulated cells express more ICAM-1 and VCAM than control cells [17]. In the $P$. chabaudi model, infected mice in the absence of ICAM-1 showed less anemia and weight loss, reduced parasite accumulation in both the spleen and liver, and higher peripheral blood parasitemia during acute stage malaria, which presented the possible role of ICAM-1 in the adhesion and pathogenesis of $P$. chabaudi [18]. Endothelial receptors have been studied to understand iRBC adherence in the microvasculature of different organs in severe malaria, and some of these receptors are well established such as ICAM1 in cerebral malaria and CSA in placental malaria [19]. However, both the mechanism and consequences of $\mathrm{PbA}$ iRBC adhesion in DBA/2 lung endothelial cells remain unknown. In 2013, endothelial protein C receptor (EPCR) was shown to be a new receptor for Plasmodium falciparum erythrocyte protein 1 (PfEMP1) in P. falciparum-induced severe malaria [20], which may result in a new branch of research on severe malaria. As its primary function, EPCR binds with activated protein C (APC) and cleaves proteaseactivated receptor 1 (PAR-1) in a specific Ras-related C3 botulinum toxin substrate 1 (RAC1) pathway, which inhibits the activation of nuclear factor- $\kappa \mathrm{B}$ and provides barrier protection [21]. The EPCR facilitates the protein C (PC) activation by the thrombin-thrombomodulin complex, promoting cytoprotective effects in vessels and tissue protection in the brain, lungs, kidneys, and liver [22]. Additionally, APC provides neuroprotective effects such as anti-inflammatory and antiapoptotic effects and protection of the blood-brain barrier, kidneys, and lungs and thus may be directly relevant to the complications associated with severe malaria [23].

Some authors proposed that in malaria, P. falciparuminfected erythrocytes prompt a decrease in EPCR levels, and, consequently, APC production is disabled, resulting in enhanced coagulation and inducing proinflammatory factors and endothelial dysfunction via PAR-1 [24]. Indeed, in vitro studies show that a purified amino-terminal cysteine-rich interdomain region (CIDR $\alpha 1)$, especially that from domain cassette 8 (DC8), a member of the group containing PfEMP1, interferes with protein $\mathrm{C}$ binding to EPCR, resulting in acquired functional PC systemic deficiency [20, 23, 25]. However, it has unexpectedly been shown that iRBCs expressing DC13 and the HB3var03 or IT4var07 variants of PfEMP1 do not bind to the EPCR of brain endothelial cells in vitro. On the other hand, it has been shown that the DC8 variant IT4var19 may bind to the EPCR, but this interaction was inhibited when human serum or plasma was added to the assay [25]. Therefore, the disagreement concerning PfEMP1-EPCR interactions indicates the need for further studies to understand the outcome of severe malaria. Notwithstanding, there is no evidence to date of $P$. berghei ANKA binding to EPCR, and the effects of EPCR on ARDS pathogenesis must be elucidated. Our study, therefore, was developed a murine model which mimics various characteristics of human ARDS [12] and in primary culture of microvascular lung endothelial cells from DBA/2 mice (PMLEC) not only to clarify the adhesion of infected erythrocytes to murine lung microvascular endothelial cells but also to understand the relevant aspects of EPCR modulation by the immune response, which can bring important contributions to understanding malaria-associated ARDS.

\section{Materials and Methods}

2.1. Experimental Outline. DBA/2 mice were infected with $10^{6}$ infected red blood cells (iRBCs) with Plasmodium berghei ANKA (PbA) and classified as ARDS-developing or HP-developing mice before death according to previously described criteria [12]. Briefly, we used two groups of infected mice: the survival group (infected control) and the euthanized group, in which the mice were euthanized on the 7 th day postinfection (10-12 mice per group). By using respiratory patterns (enhanced pause and respiratory frequency) and the degree of parasitemia as predictive criteria, we established cut-off values using receiver operating characteristic (ROC) curves for these parameters measured on the 7th dpi based on data from mice whose cause of death was known (survival group). In the survival group, for mice showing pleural effusion or red and congested lungs at necropsy, the cause of death was designated as ARDS. For mice without pleural effusion that died after 13 days postinfection with pale lungs and high levels of parasitemia, the cause of death was designated as hyperparasitemia (HP). Afterward, we retrospectively diagnosed the euthanized mice as suffering from ARDS or HP by comparing their respiratory patterns 
and parasitemia measured on the 7th dpi with the cut-off values from the survival group at the end of each experiment (20th dpi) $[14,15]$. All lung tissue, blood, and bronchoalveolar lavage (BAL) samples were collected from mice on the 7th day postinfection (dpi) always after perfusion of the right ventricle with $20 \mathrm{ml}$ of $1 \times$ PBS until the lungs remained clear.

2.2. Mice, Parasites, and Euthanasia. Male DBA/2 mice between 6 and 10 weeks old (purchased from the Department of Parasitology, University of São Paulo, Brazil) were infected with $1 \times 10^{6} \mathrm{P}$. berghei ANKA (clone 1.49l) iRBCs kindly provided by the laboratory of Dr. Maria Mota from the Institute of Molecular Medicine (IMM) in Portugal. Parasitemia and mortality were monitored daily. Parasitemia was determined by Giemsa staining and expressed as the percentage of infected red blood cells. The euthanasia of mice was performed using ketamine $(150 \mathrm{mg} / \mathrm{kg}) / x y l a z i n e ~(15 \mathrm{mg} / \mathrm{kg})$.

2.3. Determination of Respiratory Pattern. Respiratory patterns (respiratory frequency (RF), tidal volume (TV), and enhanced pause (Penh)) were monitored on the 7th dpi by an unrestrained whole-body plethysmography chamber (WBP, Buxco Electronics, USA) for 10 minutes (basal level) according to previously described methods [12].

2.4. Histopathological Analyses and Hemozoin Count. Lung tissue fragments were fixed with $10 \%$ buffered formalin for 24 hours and kept in $70 \%$ ethanol until being embedded in paraffin, and $4-5 \mu \mathrm{m}$ sections were stained with hematoxylin-eosin (H\&E). To determine the hemozoin- (Hz-) containing area, lungs from euthanized mice (ARDS-developing or HPdeveloping mice according to the predictive model on the 7th day postinfection [12]) were stained with $\mathrm{H} \& \mathrm{E}$, and 10 images were captured from each tissue sample with polarized light (400× magnification) using a Zeiss color camera (AxioCam HRc) connected to a Zeiss light microscope (Axio Imager M2). The corresponding percentage of $\mathrm{Hz}$ in each image was identified using the program ImageJ, in which the areas containing $\mathrm{Hz}$ were distinguished by brightness adjustment. The area containing $\mathrm{Hz}$ was normalized by the total area in each image.

2.5. Quantification of Gene Expression. Quantitative RT-PCR was performed for the relative quantification of gene expression from the lungs of noninfected and infected mice. RNA extraction was performed according to the "Animal Cell I" protocol from a RNeasy Mini Kit (Qiagen, USA). cDNA synthesis was performed with a $1 \mu \mathrm{g}$ RNA sample using the First-Strand cDNA Synthesis Kit RT-PCR (Roche, USA) according to the manufacturer's instructions. Finally, the PCR sample to test gene expression was prepared with SYBR Green PCR Master Mix (Applied Biosystems, USA), and the relative quantification $2^{(-\Delta \Delta \mathrm{CT})}$ method was used as described before [26]. The qRT-PCR reactions were performed in the ABI 7500 Fast instrument (Applied Biosystems, USA) using the following oligonucleotides: $\mathrm{PbA} 18 \mathrm{~S}$ (forward $5^{\prime}$-agcattaaataaagcgaatacatccttac- $3^{\prime}$; reverse $5^{\prime}$-ggagattggtttgacgtttatgtg- $3^{\prime}$ ); HPRT (forward $5^{\prime}$-aagcttgctggtgaaaagga- $3^{\prime}$; reverse $5^{\prime}$-ttgcgctcatcttaggcttt- $3^{\prime}$ ); ICAM-1 (forward $5^{\prime}$-cgaaggtggttcttctgagc- $3^{\prime}$; reverse $5^{\prime}$-gtctgctgagscccctcttg- $3^{\prime}$ ); VCAM (forward $5^{\prime}$-agtccgttctgaccatggag- $3^{\prime}$; reverse $5^{\prime}$-tgtctggagccaaacacttg- $3^{\prime}$ ); and EPCR (forward $5^{\prime}$-gacgaagtttctgccgctac- $3^{\prime}$; reverse $5^{\prime}$-ctggaggatggtgacgtttt- $\left.3^{\prime}\right)$.

2.6. Parasite Localization by Bioluminescence. DBA/2 mice were infected with the luciferase-expressing $P$. berghei parasite (parasite line 354cl4) kindly provided by the laboratory of Dr. Maria Motta from the Institute of Molecular Medicine (IMM) in Portugal. On the 7th day postinfection, $150 \mu \mathrm{l}$ of luciferin $\left(2.25 \mathrm{mg}\right.$ ) (VivoGlo $^{\mathrm{TM}}$ Luciferin, In Vivo Grade, Catalog \# P1041; Promega) was injected intraperitoneally, allowing the emission of parasite luminescence. Then, the localization of the parasite was analyzed with an IVIS Spectrum system (PerkinElmer). For this purpose, mice were sedated with isoflurane for pictures (approximately 6 minutes after the injection of luciferin). Later, they were euthanized and perfused in the right ventricle with $20 \mathrm{ml}$ of $1 \times$ PBS. After perfusion, a new image of the mice was captured, and the organs were collected and placed in sterile Petri dishes to observe the bioluminescence of each tissue.

2.7. Cytokine Quantification. The quantities of TNF, IL-6, and IL-33 in serum and culture supernatants were determined by Mouse ELISA Ready-SET-Go! ${ }^{\circledR}$ commercial kits from eBioscience (San Diego, CA, USA) specific for TNF (ref 88-7324-88), IL-6 (ref 88-7064-88), and IL-33 (ref 887333-88) according to the manufacturer's protocols.

2.8. Isolation of the Primary Microvascular Lung Endothelial Cells. Primary microvascular lung endothelial cells (PMLECs) were obtained from naive DBA/2 mice as described before $[15,27]$. Briefly, after euthanasia, the body of the animal was disinfected with iodine/alcohol. Then, the mice had all of their blood removed by cutting the carotid artery. In a laminar flow chamber, the lung tissue was cut into fragments of approximately $1 \mathrm{~mm}^{2}$ and distributed among 6-well polystyrene plates in low-glucose DMEM-supplemented culture medium (Invitrogen) (20\% heat-inactivated FBS, $40 \mu \mathrm{g} / \mathrm{ml}$ gentamicin (Invitrogen-15710064), and 1:100 antibiotic/antimycotic (Gibco-25200)) at $37^{\circ} \mathrm{C}$ and $5 \% \mathrm{CO}_{2}$. After 72 hours, the tissue fragments were removed and $50 \%$ of the medium was replaced. After 7 days of incubation, the cells were removed with trypsin $0.25 \%$ EDTA (Gibco) and replaced in a $75 \mathrm{~cm}^{2}$ culture flask. The trypsinization procedure was repeated every 5 to 7 days. Finally, the cells were cultured for 15 to 20 days (3rd and 5th passage) until being used in the trials. The purity of isolated DBA/2-PMLECs was characterized by immunofluorescence with lectin from Ulex europaeus (Sigma-Aldrich, USA-19006) and the anti-VWF (Santa Cruz Biotechnology, Inc., USA - sc14014), anti-CD31 (Abcam, UK-ab28364), anti-ACE (Abcam, UK-ab85955), anti-CD62E (Abcam, UK-ab18981), antieNOS (Abcam, UK-ab87750), and anti-VE-cadherin (Abcam, UK-ab205336) antibodies. All of the cells were stained with all of the markers indicating high purity (Figure S1). 
2.9. Plasmodium Synchronization and Enrichment of Parasitized Erythrocytes. To obtain mature forms of P. berghei ANKA, iRBCs were synchronized as described previously [28]. Briefly, iRBCs were collected from infected mice exhibiting 10 to $20 \%$ parasitemia through cardiac puncture and transferred to RPMI 1640 culture medium (Gibco, Thermo Fisher Scientific, USA) supplemented with 25\% fetal bovine serum (FBS). The iRBCs were subsequently maintained in vitro at $37^{\circ} \mathrm{C}$ for 14 hours in an atmosphere containing $5 \% \mathrm{CO}_{2}, 85 \% \mathrm{~N}_{2}$, and $10 \% \mathrm{O}_{2}$. The parasitized erythrocytes were then enriched using a magnetic separation column (Miltenyi Biotec, USA) to generate cell populations consisting of approximately $95 \%$ iRBCs, as assessed by thick blood smears. Lysate containing $P$. berghei was obtained from iRBCs subjected to several freeze-thaw cycles.

2.10. Peritoneal Macrophages. Peritoneal macrophages ( $\mathrm{M} \varphi)$ were collected from noninfected DBA/2 mice euthanized with halothane, the skin was then removed, and $5 \mathrm{ml}$ of $1 \times$ sterile cold PBS (at $4^{\circ} \mathrm{C}$ ) was inserted into the peritoneum. The liquid was then removed, aspirated with a 24 -gauge needle, and centrifuged at $1000 \mathrm{rpm}$ for 5 minutes at $4^{\circ} \mathrm{C}$. The supernatant was discarded, and the cells were resuspended in supplemented DMEM medium (20\% heat-inactivated FBS, $40 \mu \mathrm{g} / \mathrm{ml}$ gentamicin (Invitrogen-15710064), and $1: 100$ antibiotics and antimycotics (Gibco-25200)). Cells were counted in a Neubauer chamber and arranged in Transwell culture plates pretreated with $0.2 \%$ gelatin in $1 \times \mathrm{PBS}$ (gelatin from bovine skin, G9391; Sigma-Aldrich).

2.11. Transwell Assay with Endothelial Cells and Peritoneal Macrophages. Sterile $13 \mathrm{~mm}$ diameter coverslips (Knittel) were placed in 24-well culture plates. The coverslips were treated with $0.2 \%$ gelatin (gelatin from bovine skin-SigmaAldrich) diluted in $1 \times$ PBS. PMLECs were seeded in the culture plate $\left(7 \times 10^{4}\right.$ cells/well $)$ in $400 \mu \mathrm{l}$ of complete DMEM medium, and $1 \times 10^{5}$ peritoneal macrophages $(\mathrm{M} \varphi)$ were seeded in a Transwell membrane $(6.5 \mathrm{~mm}$ membrane diameter, $0.4 \mu \mathrm{m}$ membrane pore, Corning, Costar 3470 ) without contacting PMLECs on the bottom of the 24-well plate. They only shared the supernatant through the Transwell membrane. After 24 hours, $2.5 \times 10^{6}$ mature iRBCs or RBCs were added over the $\mathrm{M} \varphi$ and coincubated for 24 hours. After this time, the supernatant between the $\mathrm{M} \varphi$ and endothelial cells was collected for the quantification of cytokines by ELISA. Subsequently, endothelial cells were coincubated with 1.75 $\times 10^{6} \mathrm{PbA}$-iRBCs for the adhesion assay.

2.12. Plasmodium berghei ANKA Adhesion Assay under Static Conditions. DBA/2-PMLECs were plated in a Lab-Tek chamber slide system made of Permanox containing 8 wells $\left(3 \times 10^{4}\right.$ cells/well) (Thermo Fisher Scientific-177 455). Afterwards, TNF ( $50 \mathrm{ng} / \mathrm{ml})$ was added to the cells and incubated for 24,48 , or 72 hours. After this stimulation, synchronized $\mathrm{PbA}$-iRBCs were added for 1 hour to the culture at a ratio of $25 \mathrm{iRBCs} / \mathrm{PMLEC}$ at $37^{\circ} \mathrm{C}$ and $5 \% \mathrm{CO}_{2}$. After the incubation period, the culture medium and the removable chamber were removed, and the slides were dipped in preheated DMEM medium without FBS to eliminate unbound
PbA-iRBCs. The slides were then fixed with methanol, stained with Giemsa, and observed under an optical microscope immersion objective (1000x). The counting pattern used was the number of adhered PbA-iRBCs for every 100 DBA/2-PMLECs.

2.13. Parasite Adhesion Assay in Flowing Conditions. PMLECs between the 3rd and 5th passages were seeded $\left(8 \times 10^{4} /\right.$ well $)$ in 2 -well Permanox chamber slides from Lab-Tek (Thermo Fisher Scientific, Nunc). The cells were incubated at $37^{\circ} \mathrm{C}$ and $5 \% \mathrm{CO}_{2}$ for 24 hours. After this time, TNF was added for 24 hours or not added (for the control group). The stimulus was removed, and mature $\mathrm{PbA}-\mathrm{iRBCs}$ (25 per cell) in DMEM supplemented with $20 \%$ FBS were added and allowed to interact with the endothelial cells for 1 hour at $37^{\circ} \mathrm{C}$ in $5 \% \mathrm{CO}_{2}$. Subsequently, the wells were detached from the polystyrene slides, and the slides were added to a flow system composed of a chamber (cell adhesion flow chamber, Immunetics) that kept the slide adhered through the formation of a vacuum (coupled by a vacuum pump), a syringe pump (Insight Inc.), an inverted microscope (Zeiss Axio Vert.A1) connected to a camera (AxioCam ERc 5s, Zeiss), and a computer with an image capture system (ZEN 2011 program, AxioVision Release 4.8.2 SP2). The chamber was initially filled with DMEM medium, and then an initial photo with the parasites adhered to the PMLECDBA/2 cells was taken. Then, a medium continuous stream was run through the chamber and maintained at a flow rate of $2 \mathrm{ml} /$ hour with a pump syringe (Insight Inc.). Five images, taken every 3 minutes, of each well were captured while maintaining the same field as the initial image to determine the erythrocyte binding efficiency. Image processing and analysis were performed using ImageJ (version 1.46r). The images were opened individually in ImageJ and analyzed through the "cell counter" plugin, and all PbA-iRBC images were selected on each image. After counting all the images, the total number of PbA-iRBCs that remained in the final image (taken after 15 minutes) was recorded. The experiment was repeated with two independent cultures, each with two technical replicates. Image processing and analysis were performed in ImageJ.

2.14. Treatment with Dexamethasone. A total of $200 \mu \mathrm{l}$ $(80 \mathrm{mg} / \mathrm{kg})$ of dexamethasone $(8 \mathrm{mg} / \mathrm{ml}$ Decadronal, Aché, Brazil) was taken directly from the bottle and injected intraperitoneally (ip) on days 5 and 6 postinfection. The dexamethasone dose was chosen according to the therapeutic dose observed by Van den Steen in 2010 [29]. Control mice received $200 \mu \mathrm{l}$ of $1 \times$ PBS ip on the same days.

2.15. Lung Permeability and Edema Quantification. To investigate lung permeability, noninfected or $\mathrm{PbA}$-infected mice (dexamethasone-treated or not) on the 7th dpi were injected intravenously with $0.2 \mathrm{ml}$ of $1 \%$ Evans Blue (Sigma-Aldrich). The mice were euthanized 45 minutes later, and the lungs were weighed immediately and placed in $2 \mathrm{ml}$ of formamide (Merck) for 48 hours at $37^{\circ} \mathrm{C}$ [12]. The absorbance of the formamide was then measured at $620 \mathrm{~nm}$ and $740 \mathrm{~nm}$. The 
amount of Evans Blue staining per gram of lung tissue was calculated from a standard curve.

2.16. Measure of Primary Microvascular Lung Endothelial Cell Permeability. The increased lung vascular permeability was analyzed in DBA/2-PMLECs plated on permeable membrane inserts with $0.4 \mu \mathrm{M}$ pores (Transwell Corning) pretreated with gelatin $0.2 \%$ in $1 \times \mathrm{PBS}$ (gelatin from bovine skin, G9391, Sigma-Aldrich), coupled in 24-well polystyrene plates at a concentration of $2.2 \times 10^{4}$ cells per insert and maintained in DMEM culture at $37^{\circ} \mathrm{C}$ as previously described [15]. After 96 hours, when the cells reached confluency, $\mathrm{PbA}$ lysate was applied for 1 hour after incubation with dexamethasone $(500 \mathrm{ng} / \mathrm{ml}$ for $24 \mathrm{~h})$ or solely with $20 \%$ FBSsupplemented DMEM culture medium. The culture medium was subsequently replaced by Hank's balanced salt solution, and in the upper compartment of each insert in contact with the cells, $200 \mu \mathrm{l}$ of Evans Blue was incubated at a $2 \mathrm{mg} / \mathrm{ml}$ concentration at $37^{\circ} \mathrm{C}$. After 30 minutes, the liquid from the lower compartment was collected and analyzed in a spectrophotometer at a wavelength of $650 \mathrm{~nm}$ (NanoDrop 2000, Thermo Fisher Scientific). Finally, the concentration of Evans Blue was determined from a standard curve $(0.2 \mathrm{mg} / \mathrm{ml}$ to $0.0031 \mathrm{mg} / \mathrm{ml}$ ) as previously described [30].

\subsection{Actin Microfilament Identification by} Immunofluorescent and Morphometric Analysis of the Opening of Interendothelial Junctions. To analyze the area of the opening of interendothelial junctions (OIJs), PMLECs were plated in 24 -well plates $\left(7 \times 10^{4}\right.$ cells/well), adhered to gelatin on glass coverslips, and maintained at $37^{\circ} \mathrm{C}$ and $5 \%$ $\mathrm{CO}_{2}$. The cells were coincubated with either iRBCs or RBCs for 1 hour after incubation with dexamethasone (24 hours) or DMEM culture medium supplemented with $20 \%$ FBS, and incubations were done in triplicate. Subsequently, the cells were fixed with $3.7 \%$ formaldehyde, permeabilized with acetone at $-20^{\circ} \mathrm{C}$, and blocked with bovine serum albumin solution (1\% BSA). Actin was marked with Texas Red-X Phalloidin (T7471, Life Technologies) for 20 minutes. The cell nuclei were marked with Hoechst stain (H33342, Life Technologies). Each slide with fully confluent cells was chosen randomly, and ten to twenty pictures were taken and scanned in a "zig-zag" pattern from top to bottom. The images were acquired with an Axio Imager M2 microscope (Zeiss) using AxioCam HRc (Zeiss) and AxioVision Software, version 4.9.1.0. The total OIJ area was measured in each picture using ImageJ software (version 1.52a-NIH, USA). To calculate the OIJ, the "measure" tool and the "wand (tracing)" tool in ImageJ were used. Each image was analyzed individually, and all of the OIJs were circled with the "wand (tracing)" tool, from which the area of each space was calculated. Analysis of the differences between the openings of the interendothelial junctions following different stimuli was performed using GraphPad Prism $8^{\circledR}$ software.

2.18. TNF Blockage. TNF was blocked in DBA-PMLECs using mouse TNF neutralizing (D2H4) rabbit mAb \#11969 (Cell Signaling Technology) at a concentration of $1 \mu \mathrm{g} / \mathrm{ml}$ for 24 hours in PMLECs.
2.19. Soluble EPCR Quantification. Soluble endothelial protein $\mathrm{C}$ receptor (sEPCR) was measured with an ELISA kit (Elabscience ${ }^{\circledR}$, E-EL-M1073) according to the manufacturer's instructions.

2.20. EPCR Western Blot. Fresh frozen mouse lung tissues collected on the 7th dpi were sonicated and homogenized at $4^{\circ} \mathrm{C}$ using radioimmunoprecipitation assay (RIPA) buffer composed of $50 \mathrm{mM}$ Tris- $\mathrm{HCl} \mathrm{pH} \mathrm{8.0,150} \mathrm{mM} \mathrm{NaCl,} 0.5 \%$ sodium deoxycholate, $0.2 \%$ sodium dodecyl sulfate (SDS), $1 \mathrm{mM}$ sodium orthovanadate, $1 \mathrm{mM} \mathrm{NaF}$, and a protease inhibitor tablet. The total protein concentration was determined using a SpectraMax ${ }^{\circledR}$ Plus 384 (Molecular Devices) spectrophotometer with a $562 \mathrm{~nm}$ filter using the Pierce ${ }^{\mathrm{TM}}$ BCA Protein Assay Kit (Thermo Fisher Scientific) according to the manufacturer's instructions. Then, $30 \mu \mathrm{g}$ of protein from each sample was electrophoretically separated in a $10 \%$ polyacrylamide minigel (Bio-Rad) by SDS-PAGE at $100 \mathrm{~V}$ for 2 hours in a Mini-PROTEAN ${ }^{\circledR}$ Tetra Cell apparatus (Bio-Rad). The Kaleidoscope commercial standard Precision Plus Protein Standard (Bio-Rad) was used. Subsequently, proteins separated on the gel were transferred to PVDF (polyvinylidene difluoride, $0.2 \mu \mathrm{m}$, Bio-Rad) membranes in transfer buffer $(0.1 \mathrm{M}$ Tris, $20 \%$ methanol and MilliQ water) overnight at $4^{\circ} \mathrm{C}$ in a wet transfer apparatus at $70 \mathrm{~mA}$ constant voltage (Bio-Rad). Detection of the chemiluminescence immunochemical reaction was performed on a ChemiDoc $^{\mathrm{TM}}$ XRS+ Molecular Imager ${ }^{\circledR}$ (Bio-Rad) transilluminator with the Image $\mathrm{Lab}^{\mathrm{TM}}$ Software (Bio-Rad). Blocking of nonspecific sites was carried out after the transfer in Tris-buffered saline and Tween-20 buffer $(0.05 \mathrm{M}$ Tris, $0.1 \mathrm{M} \mathrm{NaCl}, \mathrm{pH} 7.3$, and $0.1 \%$ Tween-20, Synth) containing $3 \%$ BSA for 2 hours while stirring at room temperature (RT). The membrane was then incubated with the primary anti-EPCR antibody (\#151403, Abcam) at 1:1000 while stirring overnight at $4^{\circ} \mathrm{C}$. After washing in TBS-T, the membrane was incubated with the peroxidase-conjugated rabbit antirabbit IgG (HRP) secondary antibody (\#AP307P, Millipore) at $1: 6000$ in TBS-T for 1 hour (RT). Bands corresponding to EPCR and the housekeeping protein $\beta$-actin (mouse IgG \#NB600-501, Novus Biologicals, at $1: 40,000)$ were detected by the chemiluminescence method (Clarity Western ECL Substrate, Bio-Rad) and finally densitometrically measured by ImageJ 1.6.0 software.

2.21. Bronchoalveolar Lavage and VEGF Quantification. On the 7th dpi, infected mice (untreated or treated with dexamethasone) were anesthetized, and having bronchoalveolar lavage (BAL) collected. For that, the trachea was exposed and cannulated, and the lungs were washed once with $1.0 \mathrm{ml}$ of $1 \times$ PBS. An ELISA kit (R\&D Systems, USA) was used to quantify VEGF levels in BAL and in culture supernatant according to the manufacturer's instructions.

2.22. Transfection of EPCR by siRNA. To transfect EPCR by interference RNA assay, Lipofectamine ${ }^{\circledR}$ RNAiMAX Reagent (Invitrogen by Life Technologies) and 3 different predesigned and validated oligo silencers (Ambion by Life Technologies) were used according to the manufacturer's 
protocol. Additionally, a Silencer Select Negative Control ((C-) (Ambion, 4390843)) and a Silencer Select GAPDH Positive Control $((\mathrm{C}+)$ (Ambion, 4390849)) were employed as control reactions.

(1) siRNA1-forward: $5{ }^{\prime}$-CAACCGGACUCGGUAU GAATT- $3^{\prime}$; reverse: $5^{\prime}$-UUCAUACCGAGUCCGG UUGta-3'

(2) siRNA2-forward: $5^{\prime}$-ACGCAAAACAUGAAAG GGATT-3' ${ }^{\prime}$; reverse: $5^{\prime}$-UCCCUUUCAUGUUUUG CGUGG-3'

(3) siRNA3-forward: 5 '-CGCCCUUUGUAACUCC GAUTT-3'; reverse: $5^{\prime}$-AUCGGAGUUACAAAGG GCGCA-3'

2.23. Immunohistochemistry of ICAM-1 and VCAM in Lungs. To perform immunohistochemistry of ICAM-1 and VCAM, slides containing the paraffin tissue sections were placed in an incubator at $60^{\circ} \mathrm{C}$ for 20 minutes to melt the paraffin. Then, they were incubated in xylene twice for $15 \mathrm{~min}$ at $60^{\circ} \mathrm{C}$ and then in absolute ethanol, $95 \%$ alcohol, $70 \%$ alcohol, distilled water, and finally $1 \times \mathrm{PBS}$, pH 7.2 to 7.4. For antigen retrieval, the slides were incubated in sodium citrate buffer, $\mathrm{pH} 6$, for 45 minutes at $95^{\circ} \mathrm{C}$. Endogenous peroxidase was blocked with 3\% hydrogen peroxide for 15 minutes twice at room temperature while protected from light. The tissue was probed with rabbit polyclonal to ICAM-1 $(1: 400)$ antibody (Abcam, ab124759) and rabbit monoclonal to VCAM $(1: 600)$ antibody (Abcam, ab134047) overnight at $4^{\circ} \mathrm{C}$, and then the REVEAL mouse/rabbit kit (Spring, Code SPD-015) was used in accordance with the manufacturer's instructions. The quantification of ICAM-1 and VCAM in lung tissue was performed by calculating the marked area normalized to the total tissue section. The calculation was performed in ImageJ (version 1.50b) software using the IHC toolbox plugin [31].

2.24. Statistical Analysis. The statistical analyses were performed using GraphPad Prism ${ }^{\circledR} 5.0$ software for analysis and graphing. The data were analyzed for normality by the Kolmogorov-Smirnov test or the Shapiro-Wilk normality test and for variance with the Bartlett test. Nonparametric variables for two groups were compared by using the Mann-Whitney test. For analysis of three groups, we used the Kruskal-Wallis test followed by the Dunn's post hoc test. To compare parametrical variables for two groups, a $t$-test was employed, and for three or more groups, oneway ANOVA followed by the Bonferroni posttest was used. For the survival curves, log-rank and Gehan-BreslowWilcoxon's tests were applied. The differences between the groups were considered significant when $p \leq 0.05$ (5\%). To establish a cut-off from the data, ROC curves were generated by using the results of the control group obtained in MedCalc version 8.2.1.0.

2.25. Ethics Statement. All experiments were performed in accordance with the ethical guidelines for experiments with mice, and the protocols were approved by the Animal Health
Committee of the Biomedical Sciences Institute of the University of São Paulo (CEUA no. 24, page 16, book 03). The guidelines for animal use and care were based on the standards established by the National Council for Control of Animal Experimentation (Conselho Nacional de Controle de Experimentação Animal (CONCEA)) and Brazilian Federal Law no. 11.794.

\section{Results}

3.1. ARDS-Developing Mice Show Higher Levels of Pulmonary Parasites than HP-Developing Mice. In our previous study, it was shown that a proportion of DBA/2 mice infected with $\mathrm{PbA}-\mathrm{iRBC}$ developed singular characteristics of ARDS and died between the 7th and 12th dpi [12-15]. To investigate whether adherence is essential in the evolution of this phenotype, we observed that luciferase-expressing $P$. berghei parasites were distributed in the peripheral blood and tissues of DBA/2 mice. However, when they were perfused with $1 \times \mathrm{PBS}$, the bioluminescence (luciferase/luciferin) signal remained concentrated in the spleen and lungs and slightly in the liver especially in ARDS-developing mice (Figures 1(a)-1(c)), corroborating our published data where we showed more bioluminescence signal in ARDS mice compared to HP [14]. We demonstrated that ARDS-developing mice showed higher levels of the $18 \mathrm{~S}$ subunit $\mathrm{PbA}$ rRNA expression (Figure 1(d)) and higher hemozoin concentrations in the lungs compared to those of HP-developing mice on the 7 th dpi (Figures $1(\mathrm{e})-1(\mathrm{~g})$ ). In addition, we analyzed histological lung sections of mice that died with ARDS and found several iRBCs in close contact with endothelial cells (Figure 1(h)). These results taken together indicated that ARDS-developing mice accumulated a considerable amount of iRBCs in the lungs, suggesting their essential participation in ARDS pathogenesis.

3.2. TNF Increases P. berghei Adherence in the ARDS Experimental Model. ARDS-developing mice on the 7th dpi displayed higher TNF levels in serum compared to those of HP-developing mice (Figure 2(a)), suggesting that this inflammatory cytokine may be critical to ARDS development. We further investigated whether iRBCs could contribute to TNF release by endothelial cells. First, we demonstrated that primary microvascular lung endothelial cells (PMLECs) stimulated with iRBCs can directly contribute to TNF production (Figure 2(b)). Then, we examined the influence of TNF on the adhesion of iRBCs to PMLECs using static and flow conditions. TNF-stimulated cells increased the capacity of iRBCs to adhere to PMLECs after 24 and 72 hours in the static assay (Figures 2(c)-2(e)). In the flow adherence assay, which mimics physiologic conditions, the iRBCs had more cytoadherence with TNF than without TNF stimulation (Figures 2(f)-2(h)). Additionally, peritoneal macrophages $(\mathrm{M} \varphi)$, collected from noninfected DBA/2 mice, were seeded in Transwell membranes, and then PMLECs were seeded on the bottom of a 24-well plate with no contact with the $\mathrm{M} \varphi$ being stimulated or not by red blood cells (RBCs) or iRBCs (Figures $2(\mathrm{i})-2(\mathrm{k})) . \mathrm{M} \varphi$ stimulated by iRBCs produced more TNF than $\mathrm{M} \varphi$ without contact with iRBCs (Figure 2(j)). 


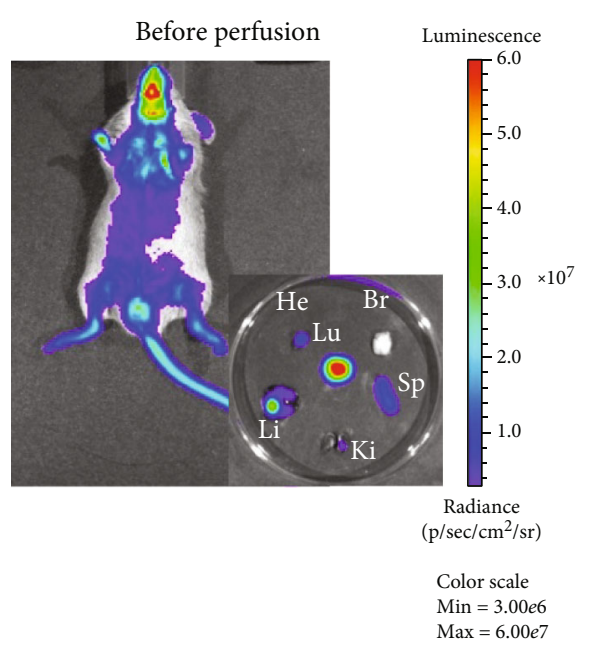

(a)

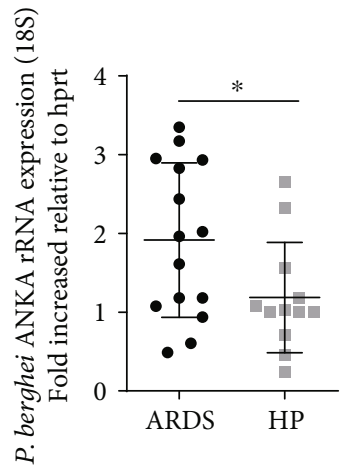

(d)

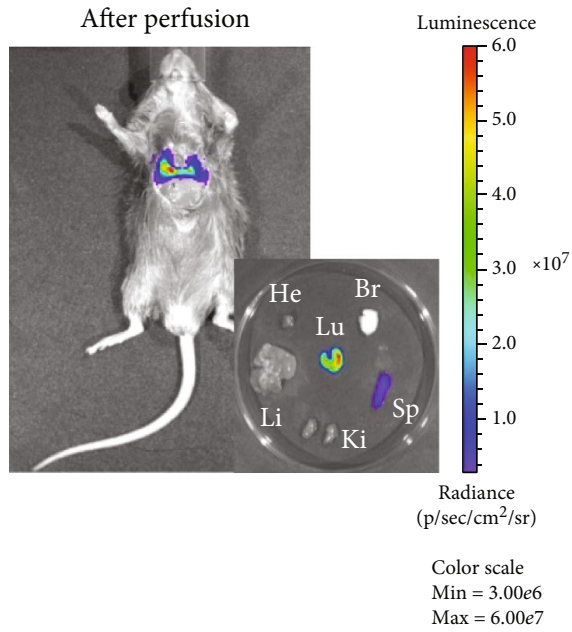

(b)

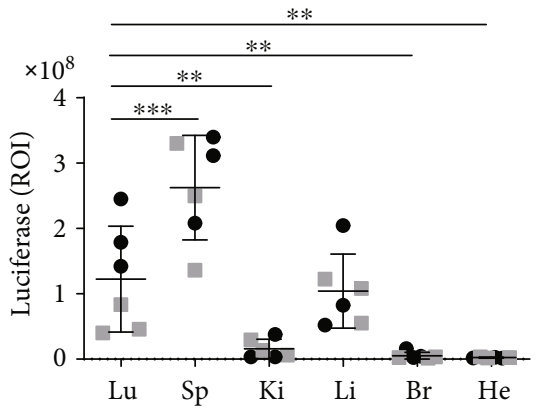

- With pleural effusion

Without pleural effusion

(c)

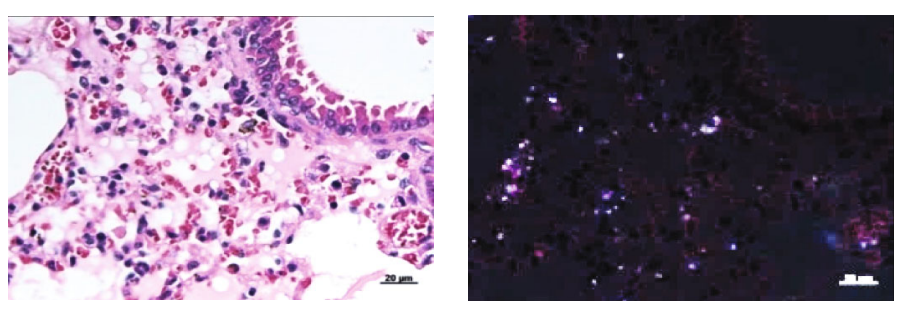

(e)

(f)

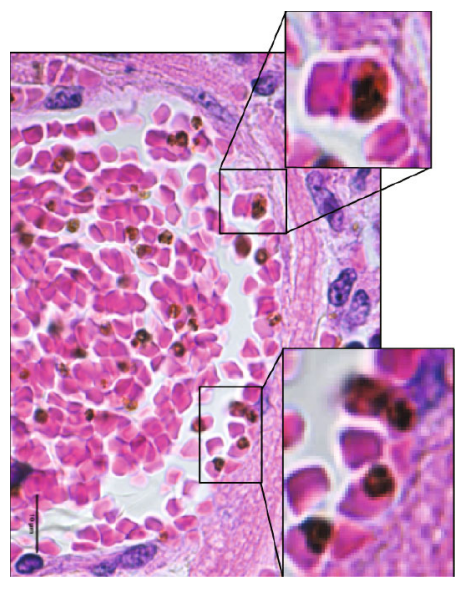

(h)

FIGURE 1: ARDS-developing mice have higher levels of pulmonary parasites than HP-developing mice. ( $a$ and $b$ ) The distribution of infected red blood cells (iRBCs) was analyzed in DBA/2 mice infected with luciferase-expressing $P$. berghei parasites (PbA-luciferase) on the 7th day postinfection (dpi) and analyzed in vivo by IVIS imaging after luciferin. (c) The organs were individually analyzed after perfusion, and results were plotted with black circles (mice with pleural effusion) and with gray squares (mice without pleural effusion); one-way ANOVA $\left({ }^{* *} p<0.01 ;{ }^{* * *} p<0.001\right)$. (d) Perfused lungs from ARDS- and HP-developing mice were collected on the 7th dpi and analyzed by rRNA gene expression of $P$. berghei ANKA (18S subunit) using the $2^{-\triangle \Delta C T}$ method. Representative image of a perfused lung collected from an ARDS-developing mouse under (e) normal and polarized lights (f) showing the hemozoin pigments, on the 7th dpi. (g) Quantification of the hemozoin area analyzed by ImageJ (magnification: 400x; scale bar: $20 \mu \mathrm{m})$. Bars represent the average \pm SD $\left({ }^{*} p<0.05 ;{ }^{* *} p<0.01\right)$. $(\mathrm{d})$ Unpaired $t$-test and (g) Mann-Whitney's test. (h) Lung histological analyses showing iRBCs in close contact with endothelial cells (inserts) in an infected mouse that died by ARDS (magnification: 630x; scale bar: $10 \mu \mathrm{m}$ ). ARDS: acute respiratory distress syndrome; HP: hyperparasitemia; Lu: lung; Sp: spleen; Ki: kidney; Li: liver; Br: brain; He: heart. 


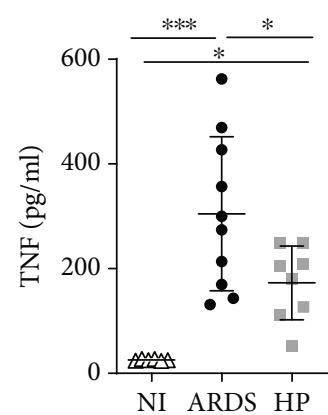

(a)

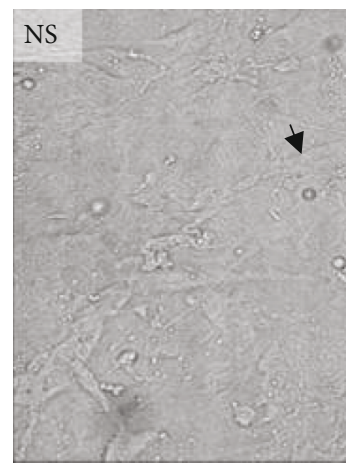

(f)

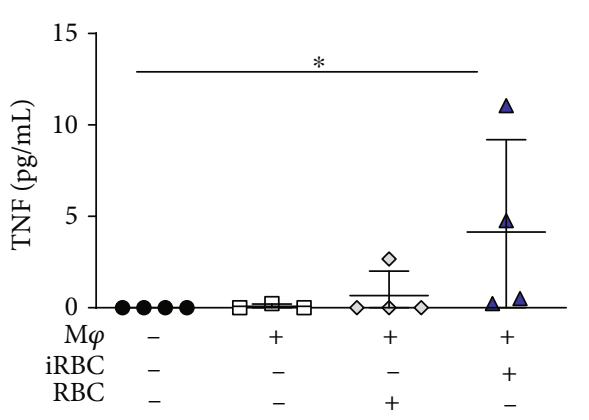

(j)

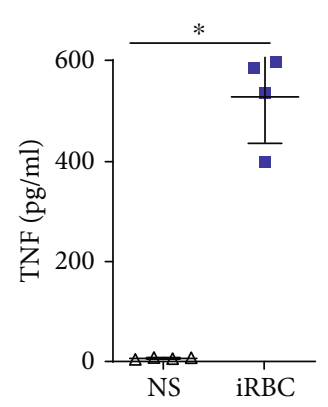

(b)

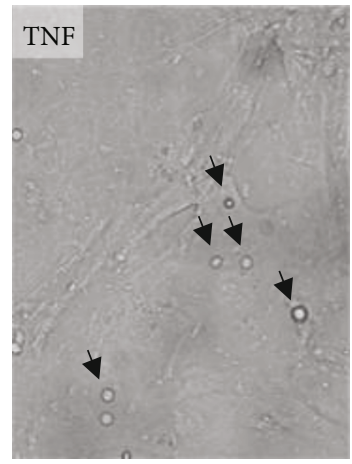

(g)

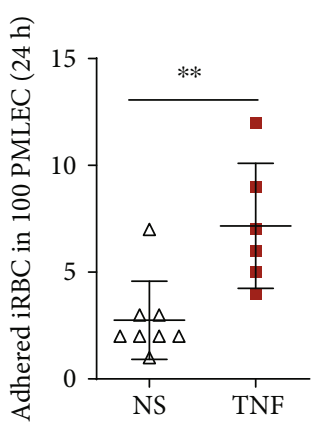

(c)

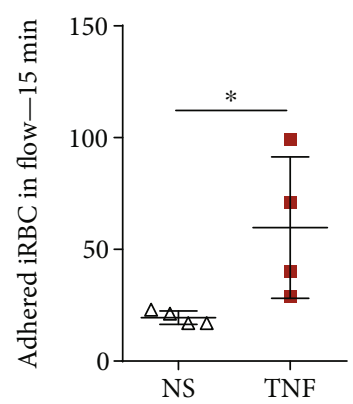

(h)

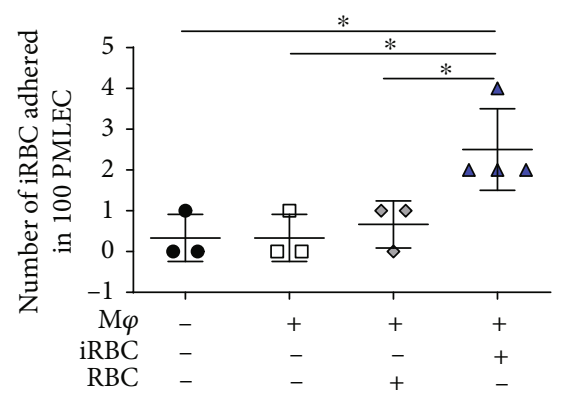

(k)

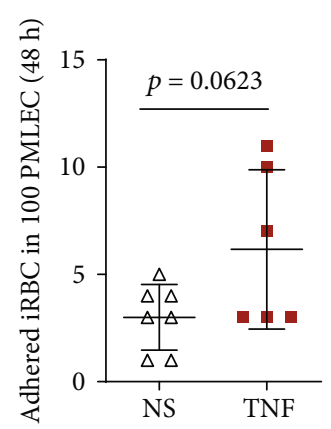

(d)

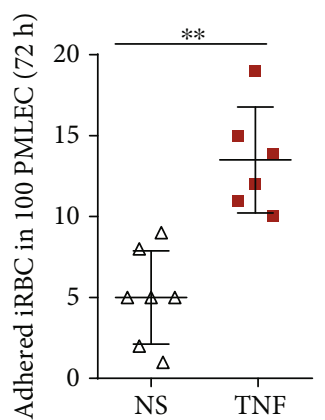

(e)

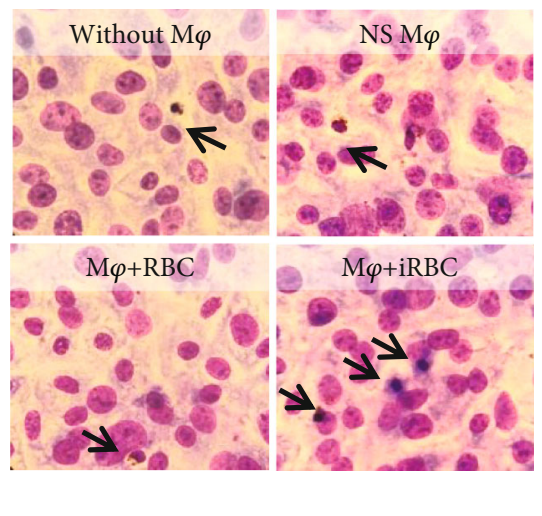

(i)

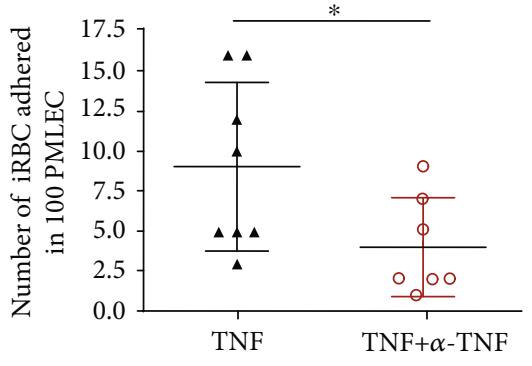

(l)

FIGURE 2: TNF increases Plasmodium berghei adherence in the ARDS experimental model. (a) Serum from ARDS- and HP-developing mice was collected on the 7th day postinfection (dpi) and submitted for TNF analysis by ELISA. (b) Primary microvascular lung endothelial cells (PMLECs) from naïve DBA/2 mice were stimulated with infected red blood cells (iRBCs), and TNF was measured in the supernatant. (c-e) PMLECs were also stimulated with TNF $(50 \mathrm{ng} / \mathrm{ml})$, and the adhesion of iRBCs to PMLECs under static conditions and (f-h) under flow conditions (after 24 hours of TNF stimulation) was analyzed. (i-k) iRBCs adhered in PMLECs in a static condition assay after coincubation with peritoneal macrophages $(\mathrm{M} \varphi)$ seeded in transwell membranes and coincubated with iRBCs or red blood cells (RBCs) for 24 hours, and then (j) TNF release was measured in the supernatant. (k) PMLECs (that had contact with the M $\varphi$ supernatant) were incubated with iRBCs having their adhesion analyzed. (l) iRBC adherence was assessed in TNF-stimulated cells and TNF-neutralized antibodies plus TNF. Bars represent the average \pm SEM. Graphs: (a) one-way ANOVA from two grouped experiments; (b-h) the MannWhitney test is representative of $(b$ and $h)$ two independent experiments and (c-e and $l)$ two grouped experiments; ( $j$ and $k)$ the KruskalWallis test is representative of two independent experiments; bars represent the average $\pm \mathrm{SD}\left({ }^{*} p<0.05 ;{ }^{* *} p<0.01 ;{ }^{* * *} p<0.001\right)$. ARDS: acute respiratory distress syndrome; HP: hyperparasitemia. Arrows in (f), (g), and (i) indicates iRBC adhered in PMLECs.

Additionally, PMLECs that were in indirect contact with $\mathrm{M} \varphi$ stimulated with iRBCs demonstrated more adherence to iRBCs than PMLECs with no previous contact with $\mathrm{M} \varphi$ (Figure 2(k)). Finally, to evaluate the contribution of TNF to the adhesion of iRBCs to PMLECs, the cells were blocked with TNF antibody, and as a result, the blockage reduced the capacity of iRBCs to adhere to PMLECs (Figure 2(1)). All these data show that ARDS-developing mice express more TNF, which contributes to iRBC adherence in endothelial cells than in HP-developing mice.

3.3. EPCR Could Contribute to P. berghei Cytoadherence. Looking for adhesion molecules that could be involved in PbA-iRBC cytoadherence in ARDS pathogenesis, we 


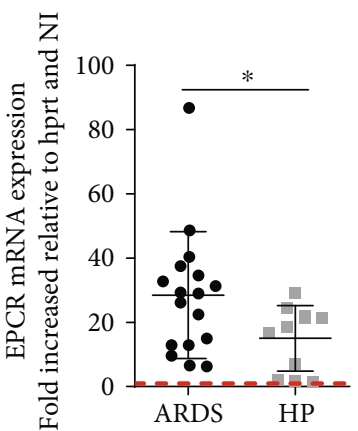

(a)

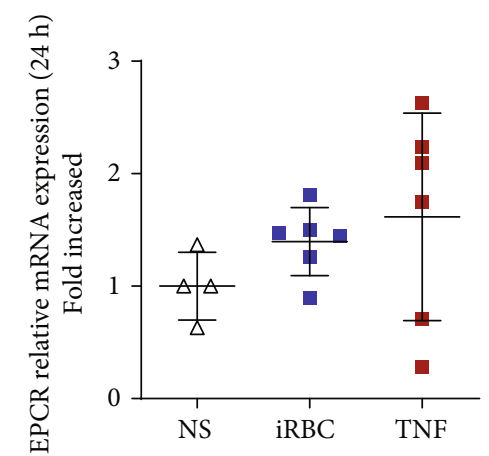

(d)

(b)
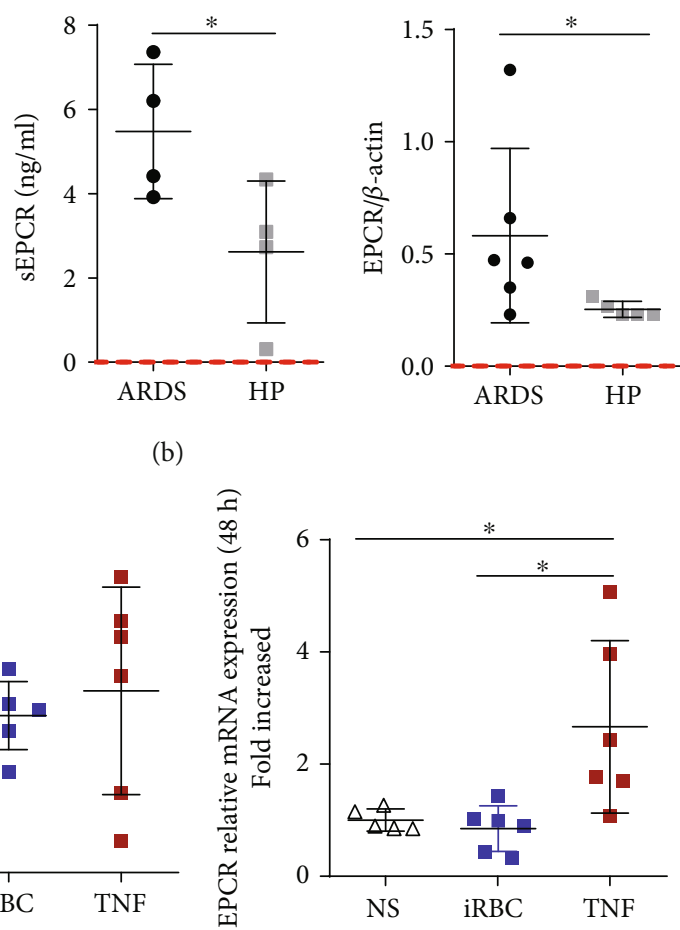

(e)

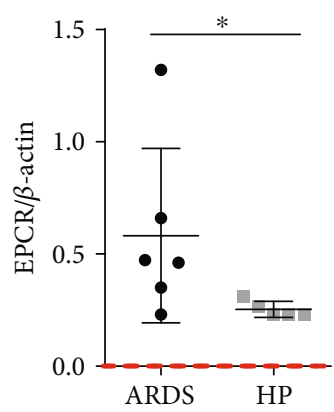

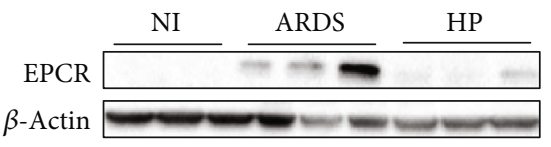

(c)

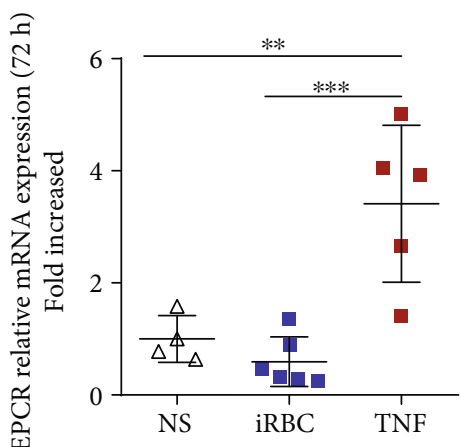

(f)

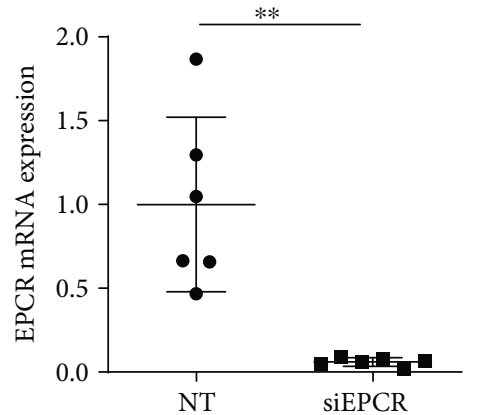

(g)

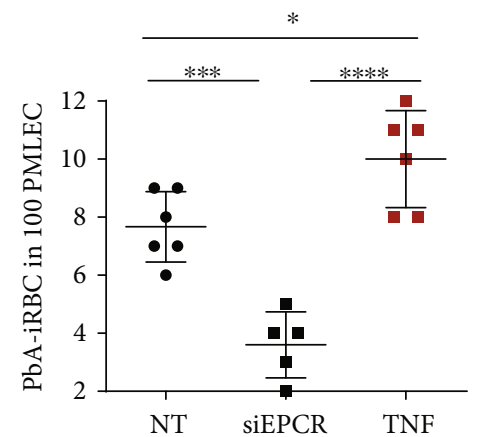

(h)

FIGURE 3: EPCR could contribute to P. berghei cytoadherence. Lungs and serum from ARDS- and HP-developing mice were analyzed by (a) EPCR mRNA expression, (b) soluble EPCR (sEPCR) in serum, and (c) EPCR protein in the lungs, on the 7th day postinfection. (d-f) Primary microvascular endothelial cells (PMLECs) were stimulated with either infected red blood cells (iRBCs) or TNF (50 $\mu \mathrm{g} / \mathrm{ml})$ for (d) 24 , (e) 48, and (f) 72 hours to analyze EPCR mRNA expression. (g) PMLECs were subjected to EPCR knockdown with siRNA, and (h) iRBC adherence in PMLECs was evaluated. ( $\mathrm{a}, \mathrm{b}$, and $\mathrm{d}$ ) The unpaired $t$-test is representative of (a) three grouped, (b) two independent, and (d) two grouped experiments. (c) The Mann-Whitney test is representative of two independent experiments. (e-h) One-way ANOVA from two grouped experiments. Bars represent the average $\pm \mathrm{SD}\left({ }^{*} p<0.05,{ }^{* *} p<0.01,{ }^{* * *} p<0.001\right.$, and ${ }^{* * * *} p<0.0001 ; n=4-7$ replicates/group). ARDS: acute respiratory distress syndrome; HP: hyperparasitemia; NS: nonstimulated cells; NT: nontransfected cells. Red dashed lines: noninfected mice.

observed that ARDS-developing mice showed higher levels of VCAM and ICAM-1 in lungs than HP-developing or noninfected mice (NI) as analyzed by immunohistochemistry (Figures S2a-S2c). Additionally, recombinant TNF upregulated the mRNA expression of ICAM-1 and VCAM in PMLECs (Figures S2d-S2i). However, the most interesting finding was the upregulation of mRNA EPCR expression in the lungs of ARDS-developing mice compared to NI mice (28.48-fold increase) and HP-developing mice (13.16fold increase) (Figure 3(a)). There was also an increase in soluble EPCR (sEPCR) (Figure 3(b)) in serum and EPCR protein in lungs (Figure 3(c)) in ARDS-developing mice when compared to HP-developing mice. We further investigated the influence of TNF on the regulation of EPCR expression in PMLECs. TNF-stimulated cells showed an upregulation of EPCR expression at 48 and 72 hours, but this was not seen with $\mathrm{PbA}$-iRBC stimulation (Figures 3(d)-3(f)). Moreover, EPCR knockdown with siRNA transfection (siEPCR) in PMLECs reduced EPCR expression compared to that in nontransfected PMLECs (Figure 3(g)). In addition, in siEPCR cells, iRBC adhesion was reduced compared to TNF-stimulated and nontransfected cells (Figure 3(h)). 
3.4. Dexamethasone Reduces VEGF, TNF, and EPCR, Protecting Mouse Lungs and PMLECs from Increased Vascular Permeability. Once TNF seemed to be important to induce $\mathrm{PbA}$-iRBC adherence and consequently ARDS development, $\mathrm{DBA} / 2$ mice were infected with $\mathrm{PbA}-\mathrm{iRBC}$ and treated with dexamethasone $(80 \mathrm{mg} / \mathrm{kg})$ on days 5 and 6 postinfection to investigate whether it could protect them from lung injury.

Dexamethasone treatment decreased TNF concentrations in the plasma (Figure 4(a)) apart from IL-6 and IL-33 concentrations in treated mice compared to those of nontreated mice (Figures S3a and S3b). Dexamethasone also downregulated EPCR (Figure 4(b)) and VCAM (Figure S2c) expression but not ICAM expression (Figure S2d) in the lungs of infected mice. The soluble EPCR concentrations in the serum and bronchoalveolar lavage (BAL) are shown (Figures 4(c) and $4(d))$. The concentration of VEGF, an essential factor to increase vascular permeability and ARDS development, also decreased after dexamethasone treatment in the BAL of infected mice on the 7th dpi (Figure 4(e)).

Consequently, we analyzed lung vascular permeability, and dexamethasone-treated infected mice were protected compared to nontreated mice (Figures 4(f)-4(h)). To clarify the mechanism that reduced lung permeability, the openings of interendothelial junctions in PMLECs were evaluated through actin analysis. The PMLECs stimulated with iRBCs increased the spaces between the interendothelial junctions and led to disruption and reorganization in the actin filaments, which were protected by treatment with dexamethasone (Figures 4(i) and 4(j)). iRBC-stimulated PMLECs also demonstrated more permeability for the Evans Blue dye in a Transwell assay compared to dexamethasone-treated PMLECs (Figure 4(k)). Additionally, dexamethasone-treated PMLECs showed a reduction in VEGF concentration compared to cells untreated with dexamethasone (Figure 4(l)). With everything considered, these data suggest that dexamethasone is capable of reducing inflammation and decreasing EPCR levels and vascular permeability in PMLECs and in the lungs of DBA/2 mice.

3.5. Anti-Inflammatory Drug Protects Mice from ARDS but Not from Malaria Infection. Dexamethasone-treated mice improved their respiratory parameters (respiratory frequency, tidal volume, and enhanced pause (Penh)) compared to infected nontreated mice on the 7th dpi (Figures 5(a)$5(c))$. On the other hand, parasitemia levels increased in the peripheral blood of dexamethasone-treated mice on the 7 th dpi (Figure 5(d)), and these mice succumbed between 8 and 20 dpi (Figure 5(e)) with characteristics of HP without edema and lower inflammatory infiltration according to the histopathological analyses (Figures 5(f) $-5(\mathrm{~g})$ ) and count of iRBC data (Figure 5(d)).

\section{Discussion}

In the present study, we describe the cytoadherence of $\mathrm{PbA}$ iRBCs in microvascular lung endothelial cells in ARDSdeveloping mice, as well as the potential contribution of the EPCR in this mechanism and, consequently, in ARDS pathogenesis. An important advantage of this study is that our animal model reproduces the physiopathological aspects found in human ARDS patients [12, 13, 32].

We have previously shown that $\mathrm{PbA}$-infected $\mathrm{DBA} / 2$ mice can develop ARDS (between 7 to 12 days after infection) or develop HP later. ARDS-developing mice show, from the 7th dpi, interstitial and lung edema, higher vascular permeability, lung opacification, and worse breathing capacity unlike HP-developing mice [12]. ARDS-developing mice also produce more neutrophil-attracting chemokines, myeloperoxidase, and reactive oxygen species resulting in an increase of neutrophils in the lungs and BAL [14]. In this work, we investigated how $\mathrm{PbA}$-iRBC interaction with endothelial cells could mediate some of those changes in the DBA/2 model, leading to one of the two different phenotypes.

It is well known that mature forms of $P$. falciparumiRBCs can adhere to the microvasculature of different organs, which is an important feature in the pathogenesis of severe malaria in humans $[5,33]$. However, there are only a few studies focusing on cytoadherence in ARDS [11, 29, 34, 35], and the mechanism of this is not entirely known.

Previously, we found that ARDS-developing mice showed a higher level of parasites in their lungs than HPdeveloping mice, which may be important to induce malaria [14]. Our work reinforces that PbAluc-iRBC accumulated in the lungs of ARDS-developing mice, which could contribute to pathogenesis. Additionally, ARDS-developing mice showed a larger hemozoin $(\mathrm{Hz})$ area in the lungs than HPdeveloping mice on the 7th dpi, which is consistent with the onset of ARDS development as patients from Thailand with ARDS development presented a significant amount of pulmonary $\mathrm{Hz}$ [36]. Some previous works suggest that $\mathrm{Hz}$, which is released from the food vacuole into circulation during erythrocyte lysis, is rapidly taken up by circulating monocytes and tissue macrophages, inducing the production of proinflammatory mediators $[37,38]$. In addition, $\mathrm{Hz}$ linked by Plasmodium DNA is a ligand for TLR 9, which activates innate immune responses in vivo and in vitro, resulting in the production of cytokines and chemokines and the upregulation of costimulatory molecules $[39,40]$ and proinflammatory mediators such as IL- $1 \beta$ via NLP3 inflammasome complex activation [38].

It is known that iRBCs adhere to endothelial cells in vivo and in vitro. Recently, PbA-iRBCs have been demonstrated to adhere to MVECs (microvascular lung endothelial cells from $\mathrm{CBA} / \mathrm{Ca}$ mice) in vitro, and TNF-stimulated cells expressed more ICAM-1 and VCAM [17]. Other studies showed that endothelial cells stimulated with TNF showed an increase in ICAM-1 expression [17, 34], corroborating our results in vivo and in vitro that recently demonstrated that TNF and ICAM-1 markers were increased in the lungs of patients who had developed the syndrome [36]. The inhibition of $P$. falciparum iRBC adherence in TNF-activated HUVECs incubated with either anti-ELAN-1 mAB BBII or anti-VCAM mAB 4B9 [41] was not observed, suggesting that other molecules could contribute to the adhesion of iRBCs. It is interesting to highlight that the parasites by themselves (PbA-iRBC or $\mathrm{PbA}$ lysate) cannot upregulate ICAM-1, VCAM, or EPCR expression in DBA/2-PMLECs. In fact, $\mathrm{PbA}$-iRBCs adhere more to TNF-stimulated 


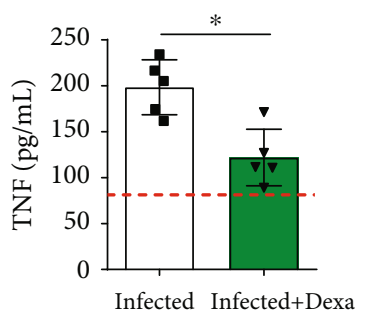

(a)

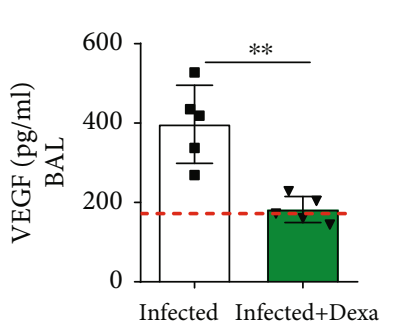

(e)

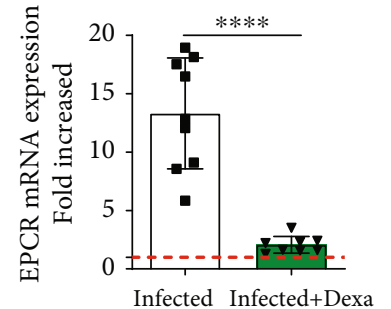

(b)

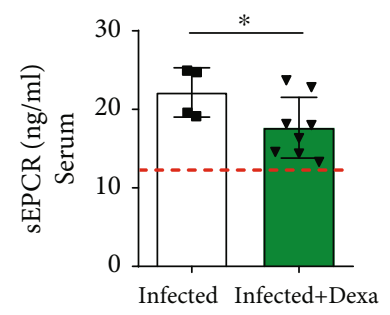

(c)

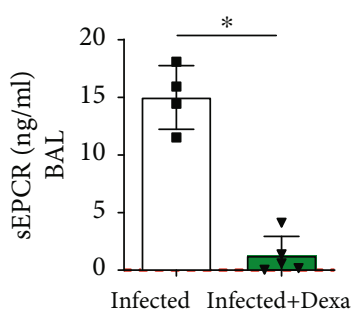

(d)

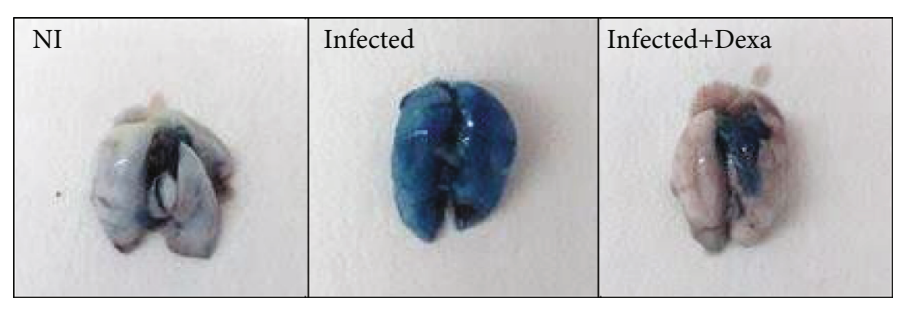

(f)

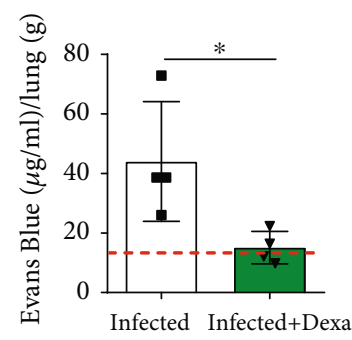

(g)
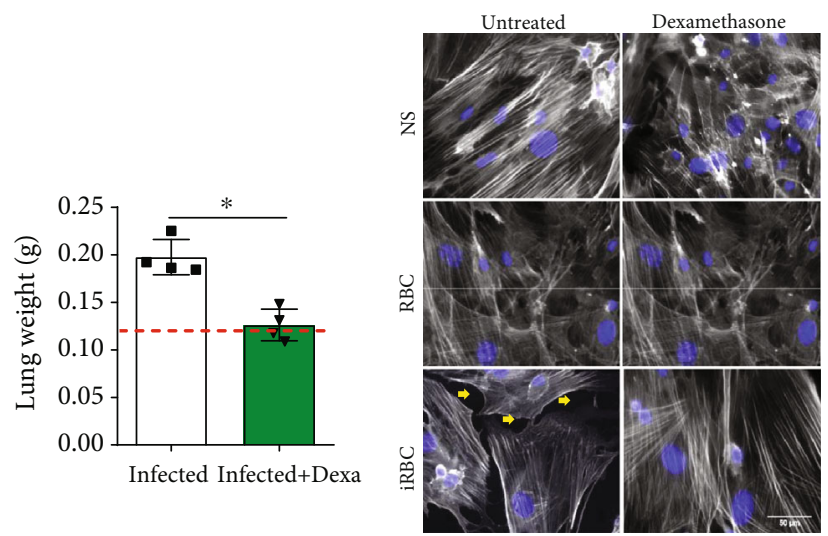

(i)

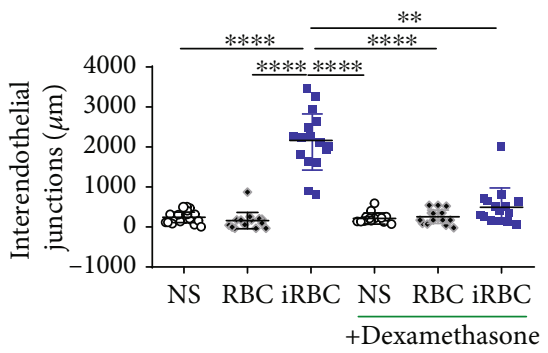

(h)

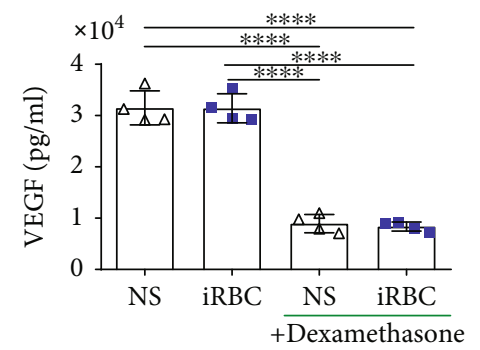

(k)

(1)

FIGURE 4: Dexamethasone reduces VEGF, TNF, and EPCR, protecting mouse lungs and PMLECs from increased vascular permeability. (a-h) Plasmodium berghei ANKA-infected DBA/2 mice were treated with dexamethasone, and their serum and perfused lungs were analyzed on the 7th day postinfection. (a) The TNF concentration in the serum, (b) EPCR mRNA expression in the lungs, (c) sEPCR concentration in both sera and (d) bronchoalveolar lavage (BAL), and (e) VEGF concentration in BAL were evaluated. (f-g) Evans Blue (EB) accumulation was measured in the lungs and $(\mathrm{h})$ the weight of the lungs was analyzed after perfusion. $(\mathrm{i}-\mathrm{j})$ Primary microvascular lung endothelial cells (PMLECs) were treated, or not, with dexamethasone and, subsequently, coincubated with either infected red blood cells (iRBCs) or red blood cells (RBCs). (i) PMLECs were stained for actin microfilaments (gray), and nuclei were stained with Hoechst stain (blue); then, the (j) openings in the interendothelial junctions (OIJ) (indicated by yellow arrows) were compared among all groups. (k) The permeability of dexamethasone-treated PMLECs was related using Evans Blue concentration in a Transwell assay. (l) VEGF levels were measured in these groups. Infected+Dexa: P. berghei ANKA-infected and dexamethasone-treated mice. Graphs: (a, c, d, g, and h) the Mann-Whitney test is representative of $(\mathrm{a}, \mathrm{d}, \mathrm{g}$, and $\mathrm{h})$ two independent and (c) two grouped experiments; ( $\mathrm{b}, \mathrm{e}$, and $\mathrm{k})$ the unpaired $t$-test is from (b) two grouped, (e) two independent, and (k) three grouped experiments; (i) the Kruskal-Wallis test is from three grouped experiments; (l) the one-way ANOVA is representative of two independent experiments. Bars represent the average $\pm \operatorname{SD}\left({ }^{*} p<0.05 ;{ }^{* *} p<0.01 ;{ }^{* * * *} p<0.0001\right)$. Red dashed lines: noninfected mice. 


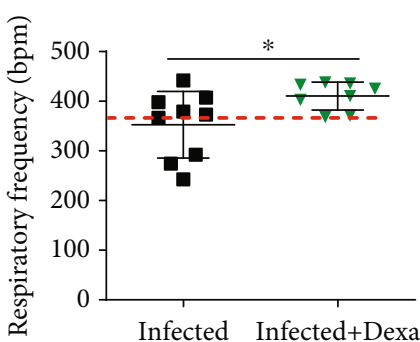

(a)

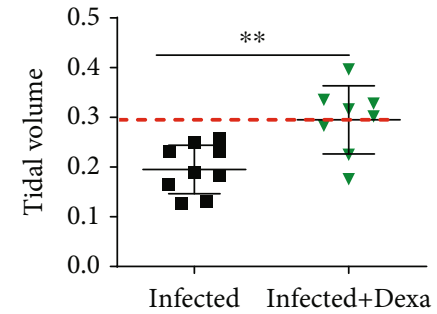

(b)

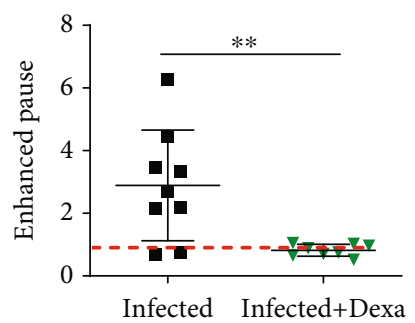

(c)

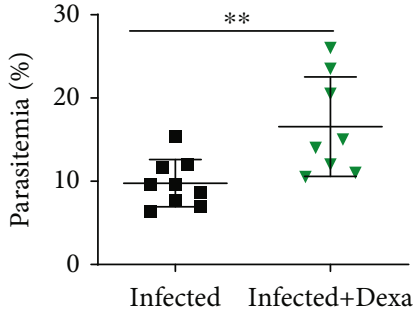

(d)

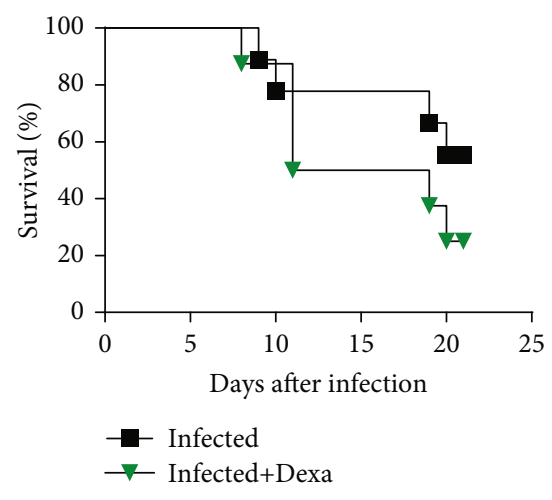

(e)

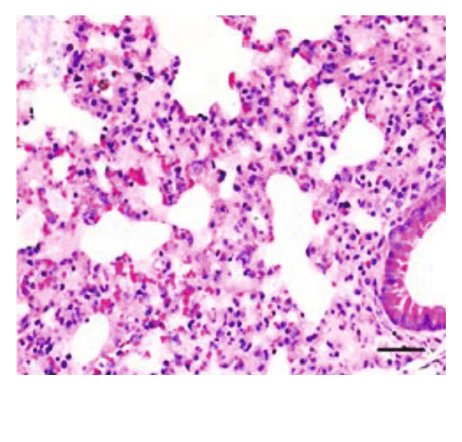

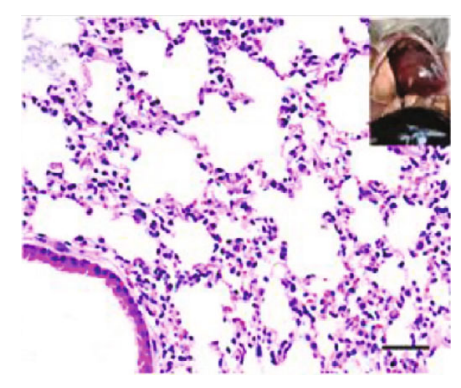

(f)

FIGURE 5: Dexamethasone protects mice from ARDS but not from malaria infection. Plasmodium berghei ANKA-infected DBA/2 mice were treated with dexamethasone and compared to infected-untreated mice on the 7th day postinfection for the following respiratory parameters: (a) respiratory frequency, (b) tidal volume, and (c) enhanced pause (Penh) analyzed in whole body plethysmography chambers. (d) Parasitemia (\%) in the peripheral blood and (e) the survival curves were compared between groups. Representative image of histological analysis of the lungs from (f) an infected mouse and (g) an infected+Dexa mouse (scale bar: $50 \mu \mathrm{m})$. Infected+Dexa: P. berghei ANKAinfected and dexamethasone-treated mice. Graphs: $(\mathrm{a}-\mathrm{d})$ the unpaired $t$-test is representative data from two independent experiments. Bars represent the average $\pm \mathrm{SD}\left({ }^{*} p<0.05 ;{ }^{* *} p<0.01\right)$. Red dashed lines: noninfected mice.

DBA/2-PMLECs than to nonstimulated cells. We previously observed the close contact between $\mathrm{PbA}-\mathrm{iRBC}$ and endothelial cell membranes in the lungs of ARDS-developing mice [32]. Nevertheless, the study reported here suggests the mechanism of $\mathrm{PbA}-\mathrm{iRBC}$ adhesion using $\mathrm{DBA} / 2$ mice that had developed ARDS. We found that ARDS-developing mice have approximately 28.5 times more EPCR expression than uninfected mice; they showed more EPCR protein in their lungs than HP-developing mice, and TNF-stimulated PMLECs displayed an upregulation in EPCR expression compared to that of nonstimulated cells (NS) or cells stimulated with iRBCs, indicating that EPCR can contribute to ARDS progression. Similarly, a study indicated that children in Papua New Guinea with severe malaria had higher antibody levels against EPCR binding to CIDR $\alpha 1$ domains compared to uncomplicated malaria and this difference was only found in older children [42]. However, in a recent study, the expression of EPCR decreased in the lungs of $P$. falciparum-infected patients who developed ARDS when compared to those who did not develop ARDS as analyzed by immunohistochemistry. The authors suggest that the change in EPCR together with thrombomodulin and in association with the deposition of hemozoin in the lungs plays an important role in the pathogenesis of ARDS [36]. Additionally, reduced sEPCR serum levels were detected in children with severe malaria, and these levels were higher in cerebral liquid from children with cerebral malaria. In spite of this, sEPCR levels were not related to mortality or neurologic manifestations at discharge or 6-month follow-up [22].

Despite the fact that $P$. berghei ANKA does not express PfEMP1, it can cause severe malaria. PfEMP-homology proteins are not displayed from $P$. berghei and exported proteins from this parasite species, responsible for iRBC cytoadherence, are not unrevealed yet. On the other hand, $P$. berghei-iRBCs have shown close contact with lung endothelial cells in ARDS-developing mice [32]. Nevertheless, a recent malaria proteomic and genetic study shows that $P$. berghei blood stages export a diversified collection of proteins [43]. One molecule that has been previously reported to mediate adhesion of iRBCs in endothelial cells is the schizont membrane-associated cytoadherence protein (SMAC) that is exported into the cytoplasm of the host erythrocyte. Mutants lacking expression of SMAC show a strongly reduced CD36-mediated iRBC sequestration [44]. Unfortunately, we have not found any correlation between CD36 mRNA levels and ARDS development in our model. Pasini et al. in 2013 identified erythrocyte-membrane-associated proteins that were related in sequestration [43]. Therefore, further studies should be developed to recognize these $P$. 
berghei proteins, especially those with the potential to connect to EPCR adhesion.

With the hypothesis that inflammation is essential to expose adherence molecules and consequently to ARDS pathogenesis, we treated DBA/2 mice with $80 \mathrm{mg} / \mathrm{kg}$ of dexamethasone. The $80 \mathrm{mg} / \mathrm{kg}$ dose is the therapeutic dose for ARDS treatment in mice observed by Van den Steen in 2010, because lower doses did not protect mice from ARDS and edema [29]. In contrast, dexamethasone was administered to patients suffering from ARDS (different etiologies) at lower doses: $5 \mathrm{mg} /$ day for 4 days in ARDS patients with bacterial pneumonia [45] and $10 \mathrm{mg}$ for 6 hours in ARDS patients with acute leucocyte leukemia [46]. In two wellconducted studies, dexamethasone failed to improve the fatality rate of cerebral malaria $[47,48]$. Unfortunately, the use of corticosteroids in acute respiratory distress syndrome (ARDS) due to malaria in humans has not been well explored [49]. In our experiments, we observed that dexamethasonetreated mice were protected from ARDS and showed the downregulation in EPCR expression, which indicates that EPCR may be necessary for iRBC adherence and the progression of disease. In other models, using endothelial cells (HUVECs), dexamethasone also had a direct effect on the downregulation of the EPCR expression [50].

EPCR binding to Plasmodium was suggested to block the interaction of EPCR with protein C [51]. On the other hand, APC binding with EPCR was required to inhibit NETosis [52]. We have previously shown that $P$. berghei and $P$. falciparum-iRBCs induced NET formation which is important to ARDS development [14].

However, there are specific domains of the PfEMP1 subfamily that do not bind to EPCR while others do [20], although the presence of serum inhibits this binding during in vitro assays [25]. Nevertheless, recently, a new study showed that using human brain microvascular endothelial cells and $10 \%$ human serum did not affect the binding between $P$. falciparum-infected red blood cells and EPCR. In addition, parasites isolated from patients with cerebral malaria displayed higher binding capacity of cytoadherence under flow conditions, compared with parasites isolated from uncomplicated malaria patients [53]. Parasite var transcripts encoding EPCR-binding domains, in association with high loads of parasites and low platelet levels, are hardy indicators of cerebral malaria. Patients with cerebral edema showed an increased transcript of parasite PfEMP1 DC8 and EPCR-binding domains. In addition, 62B1-1-CIDRa1.7 affected EPCR-APC interaction and the authors proposed a harmful role for EPCR-binding domains in these patients [54]. Therefore, the exact role of EPCR is controversial and needs to be better understood. In addition, dexamethasonetreated mice are less susceptible to increased vascular permeability. Likewise, iRBC-stimulated PMLECs treated with dexamethasone showed less permeability than untreated cells. P. berghei NK65-infected C57BL/6 mice treated with the same dose of dexamethasone also showed an increase in peripheral parasitemia and ARDS protection [29] but not an effect on pulmonary vascular permeability.

Based on our results, treatment with dexamethasone, a potent anti-inflammatory drug, decreased the serum concen- trations of IL-33, IL-6, and TNF in PbA-infected mice. In malaria, a high level of TNF was associated with severe malaria, especially in children. TNF can participate in parasite killing and, consequently, parasitemia reduction. On the other hand, increased TNF levels were observed in children with high-density parasitemia and when parasite clearance occurs, TNF decays. It is described, in a recent review, that TNF polymorphisms could control parasite development in the early stages of infection, but they can enlarge the probability of patients to develop severe malaria syndromes [55].

TNF is an inflammatory mediator strongly implicated in the development of ARDS [56] signaling through two receptors, p55 and p75, that play differential roles in pulmonary edema formation during ARDS. It was shown by a novel domain antibody $\left(\mathrm{dAb}^{\mathrm{TM}}\right)$ that p55 attenuated ventilatorinduced lung injury [57] and lung injury and edema formation in models of ARDS induced by acid aspiration [56]. Recently, the selective blockage of TNFR1 (GSK1995057 antibody) inhibited cytokine and neutrophil adhesion molecule expression in activated HMVEC-L monolayers in vitroand attenuated inflammation and signs of lung injury in primates [58]. Moreover, treatment with this antibody attenuated pulmonary neutrophilia, inflammatory cytokine release, and signs of endothelial injury in BAL and serum samples in healthy humans challenged with a low dose of inhaled endotoxin [58]. However, the precise mechanisms by which TNF is involved in severe malaria remains unknown [55].

IL-33 is a tissue-derived nuclear cytokine from the IL-1 family, and it is highly expressed during homeostasis and inflammation in endothelial, epithelial, and fibroblast-like cells, working as an alarm signal released upon cell injury or tissue damage to alert immune cells to express the ST2 receptor (IL-1RL1) [59]. Bronchial IL-33 expression is significantly increased in severe malaria patients with pulmonary edema [60]. Moreover, in PbA-induced experimental cerebral malaria (ECM), IL-33 expression is increased in the brain and ST2-deficient mice were resistant to $\mathrm{PbA}$-induced neuropathology $[61,62]$. On the other hand, $\mathrm{PbA}$-infected C57BL/6 mice treated with recombinant IL-33 presented no signs of neurological pathology associated with $\mathrm{CM}$ and had reduced production of proinflammatory cytokines and chemokines [63].

Circulating IL-6 levels are elevated in nearly all infectious, traumatic, and inflammatory states, including ARDS. Elevated levels of IL- 6 are found in the BAL and plasma of patients with ARDS and those at risk [64, 65].

Finally, we proposed the essential mechanisms of protection for dexamethasone in experimental malaria (Figure 6), suggesting that $\mathrm{PbA}$-iRBCs induce TNF release by endothelial cells and by $M \varphi$, and then TNF upregulates EPCR expression in PMLECs, increasing $\mathrm{iRBC}$ adhesion through the EPCR pathway. The adhesion of iRBCs in pulmonary endothelial cells leads to an increase in gap formation in the interendothelial junction, raising vascular permeability and consequently the formation of edema. Activated alveolar macrophages also produce TNF, which contributes to the activation of endothelial cells and possibly the recruitment of neutrophils [14] and alveolar damage. The drastic 


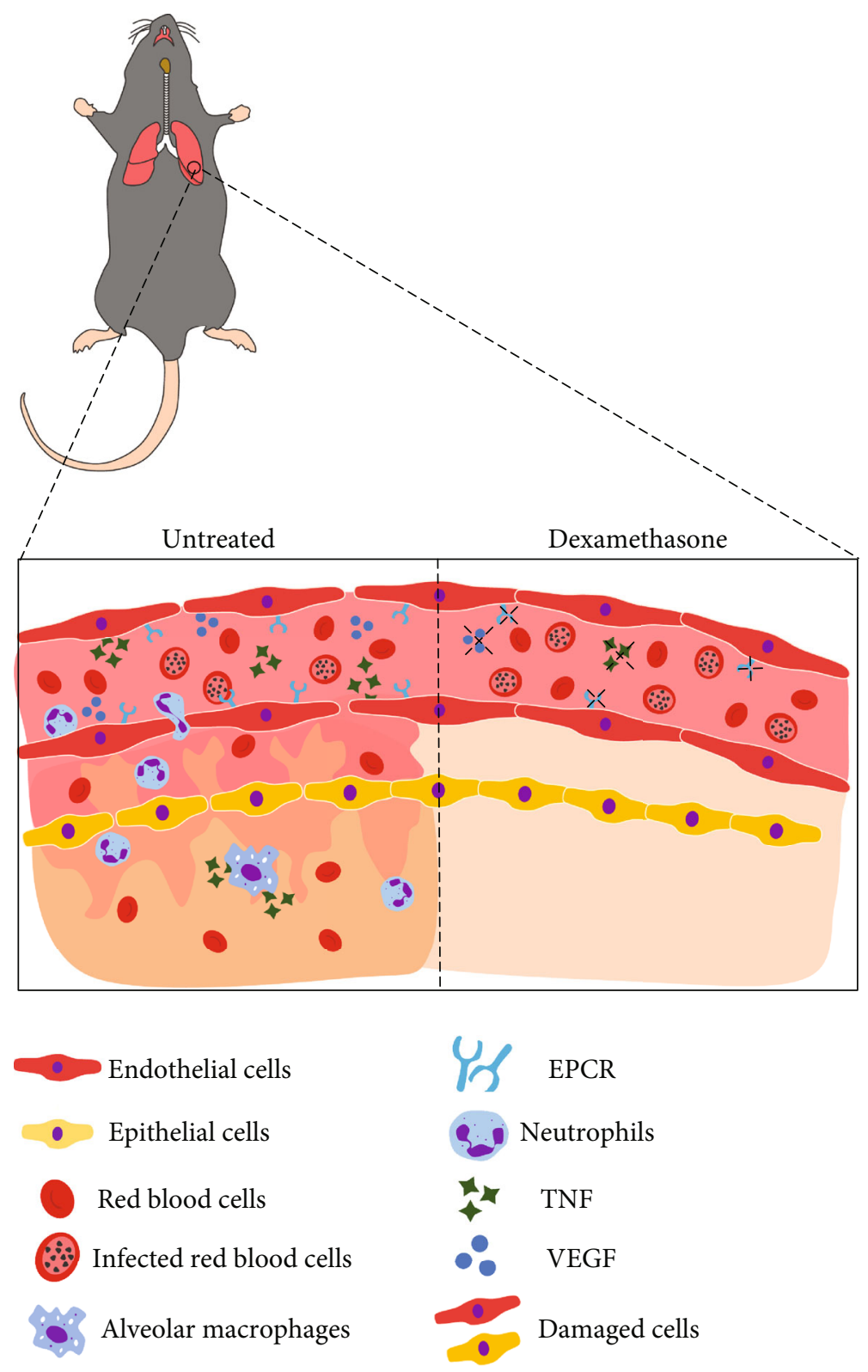

FIGURE 6: Schematic representation of ARDS development involving adhesion of iRBCs to EPCR. Plasmodium berghei ANKA-infected red blood cells (iRBCs) induce TNF release by endothelial and inflammatory cells. TNF upregulates EPCR expression in lung endothelial cells, increasing iRBC adhesion in these cells through the EPCR pathway. The adhesion of iRBCs to lung endothelial cells leads to an increase in gap formation in the interendothelial junction, an increase in vascular permeability with infiltration of inflammatory cells and red blood cells, and edema formation. Activated alveolar macrophages also produce TNF, which contributes to the activation of endothelial cells, recruitment of neutrophils, and alveolar damage. Treatment with dexamethasone decreases inflammatory cytokine release, including TNF release and, consequently, downregulates EPCR expression in lung endothelial cells; dexamethasone also decreases VEGF released by endothelial cells, protecting mice from gap formations, vascular permeability, inflammatory cell infiltration, and alveolar damage.

reduction in inflammation with dexamethasone treatment may be responsible for the increase in parasitemia and mortality. These data suggest that TNF is essential to increase the expression of EPCR and consequently increase adhesion of iRBCs in malaria-associated ARDS.

\section{Conclusions}

Our data together suggest that $P$. berghei infection induces TNF production by inflammatory and endothelial cells, lead- ing to the expression of adhesion molecules such as ICAM-1, VCAM, and especially, EPCR. These results allow us to infer that those factors could contribute to $\mathrm{PbA}-\mathrm{iRBC}$ cytoadhesion and thus suggest the participation of these mechanisms in the pathogenesis of malaria-associated ARDS. Knowing that inhibition of cytoadhesion mechanisms may improve the prognosis of infection [66], we emphasize that the processes described above may be important in the treatment of ARDS due to Plasmodium infection, acting as adjunctive therapy in association with the use of antimalarials, not only 
making the treatment more efficient but also reducing the morbidity and mortality of these patients.

\section{Data Availability}

The data used to support the findings of this study are available from the corresponding author upon request.

\section{Disclosure}

Luana dos Santos Ortolan's present address is Department of Dermatology, Carver College of Medicine, University of Iowa, 500 Newton Road, 2110 Medical Laboratories, 52242 Iowa City, IA, United States.

\section{Conflicts of Interest}

The authors declare that the research was conducted in the absence of any commercial or financial relationships that could be construed as a potential conflict of interest.

\section{Acknowledgments}

The authors thank Patricia Mendonça da Silva Amorim, Erika Paula Machado Peixoto, and Bernardo Paulo Albe for their technical assistance. This work was supported by the São Paulo Research Foundation (Fundação de Amparo à Pesquisa do Estado de São Paulo (FAPESP), Brazil), the Coordination of Improvement of Higher Level Personnel; Coordenação de Aperfeiçoamento de Pessoal de Nível Superior (CAPES); and the National Council for Scientific and Technological Development (Conselho Nacional de Desenvolvimento Científico e Tecnológico (CNPq), Brazil). LSO (CAPES and FAPESP 2013/20718-3), MKS (CAPES/ PNPD), GCM (FAPESP 2017/00077-4), TCQ (CNPq 131431/2017-0), DD (CNPq 162730/2014-4), DSC (CNPq 133890/2016-3), OM (FAPESP 2013/00981-1), CRFM (FAPESP 2016/07030-3), SE (FAPESP 2014/20451-0 and 2017/05782-8 and CNPQ 455863/2014-8) received fellowship grants.

\section{Supplementary Materials}

Supplementary Figure 1: primary microvascular lung endothelial cell characterization. PMLECs were stained by immunofluorescence with lectin from Ulex europaeus and anti-VWF, CD31, ACE, CD62E, eNOS, and VE-cadherin antibodies. Nuclei stained with Hoechst stain (blue). PMLECs: primary culture of microvascular lung endothelial cells from DBA/2 mice (scale bar: $50 \mu \mathrm{m}$ ). Supplementary Figure 2: ARDS-developing mice show more ICAM-1 and VCAM expression in the lungs than HP-developing or noninfected mice. $(\mathrm{a}-\mathrm{c}) \mathrm{DBA} / 2$ mice infected with Plasmodium berghei ANKA and lung tissues were analyzed on the 7 th day postinfection. (a) Representative immunohistochemistry images for ICAM-1 and VCAM in the lungs of NI, ARDSdeveloping, and HP-developing mice (scale bar: $100 \mu \mathrm{m}$ ). (b) Quantification of (b) ICAM-1 and (c) VCAM areas stained by immunohistochemistry. (d-i) Primary microvascular lung endothelial cells from uninfected DBA/2 mice
(PMLECs) were stimulated with Plasmodium berghei ANKA-infected red blood cells (iRBCs) or with recombinant TNF and analyzed for (d-f) ICAM-1 mRNA and (g-i) VCAM mRNA by qRT-PCR. Bars represent the average \pm SD. (b-i) One-way ANOVA from two grouped experiments $\left({ }^{*} p<0.05 ;{ }^{* *} p<0.01 ;{ }^{* * *} p<0.001\right)$. ARDS: acute respiratory distress syndrome; HP: hyperparasitemia; NI: noninfected mice; NS: nonstimulated cells. Supplementary Figure 3: dexamethasone reduced inflammation and VCAM expression but did not decrease ICAM-1 expression in $P$. berghei-infected mice. Plasmodium berghei ANKA-infected DBA/2 mice were treated with dexamethasone and compared to infecteduntreated mice. Serum and lung tissues were analyzed on the 7th day postinfection. Serum levels of (a) IL-6 and (b) IL-33 analyzed by ELISA. mRNA expression from lung tissues was evaluated for (c) VCAM and (d) ICAM-1 by qRTPCR. Bars represent the average \pm SD $\left({ }^{* *} p<0.01 ;{ }^{* * *} p<\right.$ $0.001)$. (a-b) Unpaired $t$-test representative of two independent experiments; (c-d) Mann-Whitney's test from two grouped experiments. Infected+Dexa: P. berghei ANKAinfected mice treated with dexamethasone. Red dashed lines: noninfected mice. (Supplementary Materials)

\section{References}

[1] A. G. Craig, M. F. M. Khairul, and R. P. Pradeep, "Cytoadherence and severe malaria," Malaysian Journal of Medical Sciences, vol. 19, no. 2, pp. 5-18, 2012, https://www .pubmedcentral.nih.gov/articlerender.fcgi?artid= 3431742\&tool=pmcentrez\&rendertype $=$ abstract.

[2] J. G. Beeson and G. V. Brown, "Pathogenesis of Plasmodium falciparum malaria: the roles of parasite adhesion and antigenic variation," Cellular and Molecular Life Sciences CMLS, vol. 59, no. 2, pp. 258-271, 2002, https://www.ncbi.nlm.nih .gov/pubmed/11915943.

[3] L. H. Miller, D. I. Baruch, K. Marsh, and O. K. Doumbo, "The pathogenic basis of malaria," Nature, vol. 415, no. 6872, pp. 673-679, 2002, https://www.ncbi.nlm.nih.gov/pubmed/ 11832955.

[4] B. M. Greenwood, D. A. Fidock, D. E. Kyle et al., "Malaria: progress, perils, and prospects for eradication," Journal of Clinical Investigation, vol. 118, no. 4, pp. 1266-1276, 2008, https://www.pubmedcentral.nih.gov/articlerender.fcgi?artid= 2276780\&tool $=$ pmcentrez\&rendertype $=$ abstract.

[5] B. Pouvelle, P. A. Buffet, C. Lépolard, A. Scherf, and J. Gysin, "Cytoadhesion of Plasmodium falciparum ring-stage-infected erythrocytes," Nature Medicine, vol. 6, no. 11, pp. 1264 1268, 2000, https://www.ncbi.nlm.nih.gov/pubmed/11062539.

[6] L. Rénia, S. Wu Howland, C. Claser et al., "Cerebral malaria: mysteries at the blood-brain barrier," Virulence, vol. 3, no. 2, pp. 193-201, 2012, https://www.pubmedcentral.nih.gov/ articlerender.fcgi? artid $=3396698$ \&tool=pmcentrez\&rendertype $=$ abstract.

[7] J. Grommes and O. Soehnlein, "Contribution of neutrophils to acute lung injury," Molecular Medicine, vol. 17, no. 3-4, pp. 293-307, 2011, https://www.pubmedcentral.nih.gov/ articlerender.fcgi? artid=3060975\&tool=pmcentrez\&rendertype $=$ abstract.

[8] M. Bhatia, R. L. Zemans, and S. Jeyaseelan, "Role of chemokines in the pathogenesis of acute lung injury," American 
Journal of Respiratory Cell and Molecular Biology, vol. 46, no. 5, pp. 566-572, 2012, https://www.ncbi.nlm.nih.gov/ pubmed/22323365.

[9] G. Matute-Bello and T. R. Martin, "Science review: apoptosis in acute lung injury," Critical Care, vol. 7, no. 5, pp. 355-358, 2003, https://www.pubmedcentral.nih.gov/articlerender . fcgi? artid=270707\&tool=pmcentrez\&rendertype $=$ abstract.

[10] P. E. Van den Steen, K. Deroost, J. Deckers, E. Van Herck, S. Struyf, and G. Opdenakker, "Pathogenesis of malariaassociated acute respiratory distress syndrome," Trends in Parasitology, vol. 29, no. 7, pp. 346-358, 2013, https://www.ncbi .nlm.nih.gov/pubmed/23742967.

[11] F. E. Lovegrove, S. A. Gharib, L. Peña-Castillo et al., "Parasite burden and CD36-mediated sequestration are determinants of acute lung injury in an experimental malaria model," PLoS Pathogens, vol. 4, no. 5, article e1000068, 2008https://www .pubmedcentral.nih.gov/articlerender.fcgi?artid= 2364663\&tool $=$ pmcentrez\&rendertype $=$ abstract.

[12] L. S. Ortolan, M. K. Sercundes, R. Barboza et al., "Predictive criteria to study the pathogenesis of malaria-associated ALI/ARDS in mice," Mediators of Inflammation, vol. 2014, Article ID 872464, 12 pages, 2014, https://www .pubmedcentral.nih.gov/articlerender.fcgi?artid= 4167651\&tool=pmcentrez\&rendertype $=$ abstract.

[13] S. Epiphanio, M. G. Campos, A. Pamplona et al., "VEGF promotes malaria-associated acute lung injury in mice," PLoS Pathogens, vol. 6, no. 5, article e1000916, 2010https://www .pubmedcentral.nih.gov/articlerender.fcgi? artid= 2873913\&tool=pmcentrez\&rendertype=abstract.

[14] M. K. Sercundes, L. S. Ortolan, D. Debone et al., “Targeting neutrophils to prevent malaria-associated acute lung injury/acute respiratory distress syndrome in mice," PLOS Pathogens, vol. 12, no. 12, article e1006054, 2016.

[15] M. L. M. Pereira, L. S. Ortolan, M. K. Sercundes et al., “Association of heme oxygenase 1 with lung protection in malariaassociated ALI/ARDS," Mediators of Inflammation, vol. 2016, Article ID 4158698, 12 pages, 2016.

[16] T.-T. Pham, M. Verheijen, L. Vandermosten et al., "Pathogenic $\mathrm{CD}^{+} \mathrm{T}$ cells cause increased levels of VEGF-A in experimental malaria-associated acute respiratory distress syndrome, but therapeutic VEGFR inhibition is not effective," Frontiers in Cellular and Infection Microbiology, vol. 7, pp. 110, 2017.

[17] F. El-Assaad, J. Wheway, A. J. Mitchell et al., "Cytoadherence of Plasmodium berghei-infected red blood cells to murine brain and lung microvascular endothelial cells In Vitro," Infection and Immunity, vol. 81, no. 11, pp. 39843991, 2013, https://www.ncbi.nlm.nih.gov/pubmed/ 23940206.

[18] D. A. Cunningham, J. Lin, T. Brugat et al., "ICAM-1 is a key receptor mediating cytoadherence and pathology in the Plasmodium chabaudi malaria model," Malaria Journal, vol. 16, no. 1, p. 185, 2017, https://malariajournal.biomedcentral .com/articles/10.1186/s12936-017-1834-8.

[19] W. C. Aird, L. O. Mosnier, and R. M. Fairhurst, "Plasmodium falciparum picks (on) EPCR,” Blood, vol. 123, no. 2, pp. 163167, 2014.

[20] L. Turner, T. Lavstsen, S. S. Berger et al., "Severe malaria is associated with parasite binding to endothelial protein C receptor," Nature, vol. 498, no. 7455, pp. 502-505, 2013, https://www.pubmedcentral.nih.gov/articlerender.fcgi?artid= $3870021 \&$ tool $=$ pmcentrez\&rendertype $=$ abstract.
[21] L. V. M. Rao, C. T. Esmon, and U. R. Pendurthi, "Review article endothelial cell protein $C$ receptor: a multiliganded and multifunctional receptor," Blood, vol. 124, no. 10, pp. 15531563, 2014.

[22] E. Shabani, R. O. Opoka, P. Bangirana et al., "The endothelial protein $C$ receptor rs867186-GG genotype is associated with increased soluble EPCR and could mediate protection against severe malaria," Scientific Reports, vol. 6, no. 1, 2016.

[23] L. O. Mosnier and T. Lavstsen, "The role of EPCR in the pathogenesis of severe malaria," Thrombosis Research, vol. 141, Supplement 2, pp. S46-S49, 2016.

[24] C. A. Moxon, S. C. Wassmer, D. A. Milner Jr. et al., "Loss of endothelial protein $C$ receptors links coagulation and inflammation to parasite sequestration in cerebral malaria in African children," Blood, vol. 122, no. 5, pp. 842-851, 2013.

[25] Y. Azasi, G. Lindergard, A. Ghumra, J. Mu, L. H. Miller, and J. A. Rowe, "Infected erythrocytes expressing DC13 PfEMP1 differ from recombinant proteins in EPCR-binding function," Proceedings of the National Academy of Sciences, vol. 115, no. 5, pp. 1063-1068, 2018.

[26] K. J. Livak and T. D. Schmittgen, "Analysis of Relative Gene Expression Data Using Real-Time Quantitative PCR and the $2_{\mathrm{T}}^{-\Delta \Delta \mathrm{C}}$ Method," Methods, vol. 25, no. 4, pp. 402-408, 2001, https://www.ncbi.nlm.nih.gov/pubmed/11846609.

[27] S. F. Chen, X. Fei, and S. H. Li, "A new simple method for isolation of microvascular endothelial cells avoiding both chemical and mechanical injuries," Microvascular Research, vol. 50, no. 1, pp. 119-128, 1995, https://www.ncbi.nlm.nih.gov/ pubmed/7476573.

[28] W. Trager and J. B. Jensen, "Human malaria parasites in continuous culture," Science, vol. 193, no. 4254, pp. 673675, 1976.

[29] P. E. Van den Steen, N. Geurts, K. Deroost et al., "Immunopathology and dexamethasone therapy in a new model for malaria-associated acute respiratory distress syndrome," American Journal of Respiratory and Critical Care Medicine, vol. 181, no. 9, pp. 957-968, 2010, https://www.ncbi.nlm.nih .gov/pubmed/20093644.

[30] C. M. Thumwood, N. H. Hunt, I. A. Clark, and W. B. Cowden, "Breakdown of the blood-brain barrier in murine cerebral malaria," Parasitology, vol. 96, no. 3, pp. 579-589, 1988, https://www.cambridge.org/core/product/identifier/ S0031182000080203/type/journal_article.

[31] J. Shu, G. Qiu, and M. Ilyas, "Immunohistochemistry (IHC) image analysis toolbox," 2015, https://rsb.info.nih.gov/ij/ plugins/ihc-toolbox/index.html.

[32] E. H. Aitken, E. M. Negri, R. Barboza et al., "Ultrastructure of the lung in a murine model of malaria-associated acute lung injury/acute respiratory distress syndrome," Malaria Journal, vol. 13, no. 1, p. 230, 2014.

[33] P. Pino, I. Vouldoukis, J.. P. Kolb et al., "Plasmodium falciparum-infected erythrocyte adhesion induces caspase activation and apoptosis in human endothelial cells," The Journal of Infectious Diseases, vol. 187, no. 8, pp. 1283-1290, 2003, https://www.ncbi.nlm.nih.gov/pubmed/12696008.

[34] B. De las Salas, C. Segura, A. Pabón, S. C. P. Lopes, F. T. M. Costa, and S. Blair, "Adherence to human lung microvascular endothelial cells (HMVEC-L) of Plasmodium vivax isolates from Colombia," Malaria Journal, vol. 12, no. 1, p. 347, 2013, http://www.pubmedcentral.nih.gov/articlerender .fcgi? artid $=3850517$ \&tool $=$ pmcentrez\&rendertype $=$ abstract. 
[35] H. A. D. Lagasse, I. U. Anidi, J. M. Craig et al., "Recruited monocytes modulate malaria-induced lung injury through CD36mediated clearance of sequestered infected erythrocytes," Journal of Leukocyte Biology, vol. 99, no. 5, pp. 659-671, 2016.

[36] S. Maknitikul, N. Luplertlop, G. E. R. Grau, and S. Ampawong, "Dysregulation of pulmonary endothelial protein $\mathrm{C}$ receptor and thrombomodulin in severe falciparum malaria-associated ARDS relevant to hemozoin," PLoS One, vol. 12, no. 7, article e0181674, 2017.

[37] M. Jaramillo, M. Godbout, and M. Olivier, "Hemozoin induces macrophage chemokine expression through oxidative stressdependent and -independent mechanisms," The Journal of Immunology, vol. 174, no. 1, pp. 475-484, 2005, https://www .ncbi.nlm.nih.gov/pubmed/15611273.

[38] M. T. Shio, F. A. Kassa, M. J. Bellemare, and M. Olivier, "Innate inflammatory response to the malarial pigment hemozoin," Microbes and Infection, vol. 12, no. 12-13, pp. 889-899, 2010.

[39] C. Coban, K. J. Ishii, T. Kawai et al., "Toll-like receptor 9 mediates innate immune activation by the malaria pigment hemozoin," The Journal of Experimental Medicine, vol. 201, no. 1, pp. 19-25, 2005, http://www.jem.org/lookup/doi/10.1084/jem .20041836

[40] P. Parroche, F. N. Lauw, N. Goutagny et al., "Malaria hemozoin is immunologically inert but radically enhances innate responses by presenting malaria DNA to Toll-like receptor 9," Proceedings of the National Academy of Sciences, vol. 104, no. 6, pp. 1919-1924, 2007, https://www.pubmedcentral.nih .gov/articlerender.fcgi?artid=1794278\&tool= pmcentrez\&rendertype $=$ abstract.

[41] C. F. Ockenhouse, T. Tegoshi, Y. Maeno et al., "Human vascular endothelial cell adhesion receptors for Plasmodium falciparum-infected erythrocytes: roles for endothelial leukocyte adhesion molecule 1 and vascular cell adhesion molecule 1," Journal of Experimental Medicine, vol. 176, no. 4, pp. 1183-1189, 1992, https://www.ncbi.nlm.nih.gov/ pubmed/1383378.

[42] J. S. Rambhatla, L. Turner, L. Manning et al., "Acquisition of antibodies against endothelial protein $c$ receptor-binding domains of Plasmodium falciparum erythrocyte membrane protein 1 in children with severe malaria," The Journal of Infectious Diseases, vol. 219, no. 5, pp. 808-818, 2019.

[43] E. M. Pasini, J. A. Braks, J. Fonager et al., "Proteomic and genetic analyses demonstrate that Plasmodium berghei blood stages export a large and diverse repertoire of proteins," Molecular \& Cellular Proteomics, vol. 12, no. 2, pp. 426448, 2013.

[44] J. Fonager, E. M. Pasini, J. A. M. Braks et al., "Reduced CD36dependent tissue sequestration of Plasmodium-infected erythrocytes is detrimental to malaria parasite growth in vivo," The Journal of Experimental Medicine, vol. 209, no. 1, pp. 93-107, 2012, https://www.pubmedcentral.nih.gov/articlerender .fcgi? artid=3260870\&tool=pmcentrez\&rendertype $=$ abstract.

[45] S. C. A. Meijvis, H. Hardeman, H. H. F. Remmelts et al., "Dexamethasone and length of hospital stay in patients with community-acquired pneumonia: a randomised, doubleblind, placebo-controlled trial," The Lancet, vol. 377, no. 9782, pp. 2023-2030, 2011.

[46] É. Azoulay, E. Canet, E. Raffoux et al., "Dexamethasone in patients with acute lung injury from acute monocytic leukaemia," The European Respiratory Journal, vol. 39, no. 3, pp. 648-653, 2012.
[47] D. A. Warrell, S. Looareesuwan, M. J. Warrell et al., "Dexamethasone proves deleterious in cerebral malaria," New England Journal of Medicine, vol. 306, no. 6, pp. 313-319, 1982.

[48] S. L. Hoffman, D. Rustama, N. H. Punjabi et al., "High-dose dexamethasone in quinine-treated patients with cerebral malaria: a double-blind, placebo-controlled trial," The Journal of Infectious Diseases, vol. 158, no. 2, pp. 325-331, 1988, https://www.ncbi.nlm.nih.gov/pubmed/3042874.

[49] G. Pasvol, "The treatment of complicated and severe malaria," British Medical Bulletin, vol. 75-76, no. 1, pp. 29-47, 2005.

[50] Y. Gao, G. Ma, S. Liu, Y. Teng, Y. Wang, and Y. Su, "Thalidomide and multiple myeloma serum synergistically induce a hemostatic imbalance in endothelial cells in vitro," Thrombosis Research, vol. 135, no. 6, pp. 1154-1159, 2015.

[51] S. Sampath, A. J. Brazier, M. Avril et al., "Plasmodium falciparum adhesion domains linked to severe malaria differ in blockade of endothelial protein C receptor," Cellular Microbiology, vol. 17, no. 12, pp. 1868-1882, 2015.

[52] L. D. Healy, C. Puy, J. A. Fernández et al., “Activated protein C inhibits neutrophil extracellular trap formation in vitro and activation in vivo," The Journal of Biological Chemistry, vol. 292, no. 21, pp. 8616-8629, 2017.

[53] J. Storm, J. S. Jespersen, K. B. Seydel et al., "Cerebral malaria is associated with differential cytoadherence to brain endothelial cells," EMBO Molecular Medicine, vol. 11, no. 2, article e9164, 2019.

[54] A. Kessler, S. Dankwa, M. Bernabeu et al., "Linking EPCRbinding PfEMP1 to brain swelling in pediatric cerebral malaria," Cell Host \& Microbe, vol. 22, no. 5, pp. 601-614.e5, 2017.

[55] C. Penha-Gonçalves, "Genetics of malaria inflammatory responses: a pathogenesis perspective," Frontiers in Immunology, vol. 10, pp. 1-15, 2019.

[56] M. R. Wilson, K. Wakabayashi, S. Bertok et al., "Inhibition of TNF receptor p55 by a domain antibody attenuates the initial phase of acid-induced lung injury in mice," Frontiers in Immunology, vol. 8, pp. 1-12, 2017.

[57] M. R. Wilson, M. E. Goddard, K. P. O'Dea, S. Choudhury, and M. Takata, "Differential roles of p55 and p75 tumor necrosis factor receptors on stretch-induced pulmonary edema in mice," American Journal of Physiology-Lung Cellular and Molecular Physiology, vol. 293, no. 1, pp. L60-L68, 2007, https://www.physiology.org/doi/10.1152/ajplung.00284.2006.

[58] A. Proudfoot, A. Bayliffe, C. M. O’Kane et al., "Novel antitumour necrosis factor receptor-1 (TNFR1) domain antibody prevents pulmonary inflammation in experimental acute lung injury," Thorax, vol. 73, no. 8, pp. 723-730, 2018, https://thorax.bmj.com/lookup/doi/10.1136/thoraxjnl2017-210305.

[59] C. Cayrol and J. P. Girard, "Interleukin-33 (IL-33): a nuclear cytokine from the IL-1 family," Immunological Reviews, vol. 281, no. 1, pp. 154-168, 2018.

[60] S. Ampawong, U. Chaisri, P. Viriyavejakul et al., "A potential role for interleukin-33 and $\gamma$-epithelium sodium channel in the pathogenesis of human malaria associated lung injury," Malaria Journal, vol. 14, no. 1, pp. 1-15, 2015.

[61] J. Palomo, F. Reverchon, J. Piotet et al., "Critical role of IL-33 receptor ST2 in experimental cerebral malaria development," European Journal of Immunology, vol. 45, no. 5, pp. 13541365, 2015.

[62] F. Reverchon, S. Mortaud, M. Sivoyon et al., "IL-33 receptor ST2 regulates the cognitive impairments associated with 
experimental cerebral malaria," PLoS Pathogens, vol. 13, no. 4, article e1006322, 2017.

[63] A. G. Besnard, R. Guabiraba, W. Niedbala et al., "IL-33-mediated protection against experimental cerebral malaria is linked to induction of type 2 innate lymphoid cells, M2 macrophages and regulatory T cells," PLoS Pathogens, vol. 11, no. 2, article e1004607, 2015.

[64] W. Y. Park, R. B. Goodman, K. P. Steinberg et al., "Cytokine balance in the lungs of patients with acute respiratory distress syndrome," American Journal of Respiratory and Critical Care Medicine, vol. 164, no. 10, pp. 1896-1903, 2001.

[65] A. Takala, I. Jousela, O. Takkunen et al., "A prospective study of inflammation markers in patients at risk of indirect acute lung injury," Shock, vol. 17, no. 4, pp. 252-257, 2002, https:// www.ncbi.nlm.nih.gov/pubmed/11954822.

[66] J. W. Lin, J. Sodenkamp, D. Cunningham et al., "Signatures of malaria-associated pathology revealed by high-resolution whole- blood transcriptomics in a rodent model of malaria," Scientific Reports, vol. 7, no. 1, pp. 1-13, 2017. 


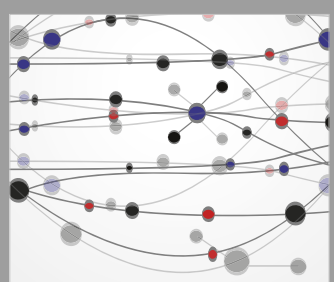

The Scientific World Journal
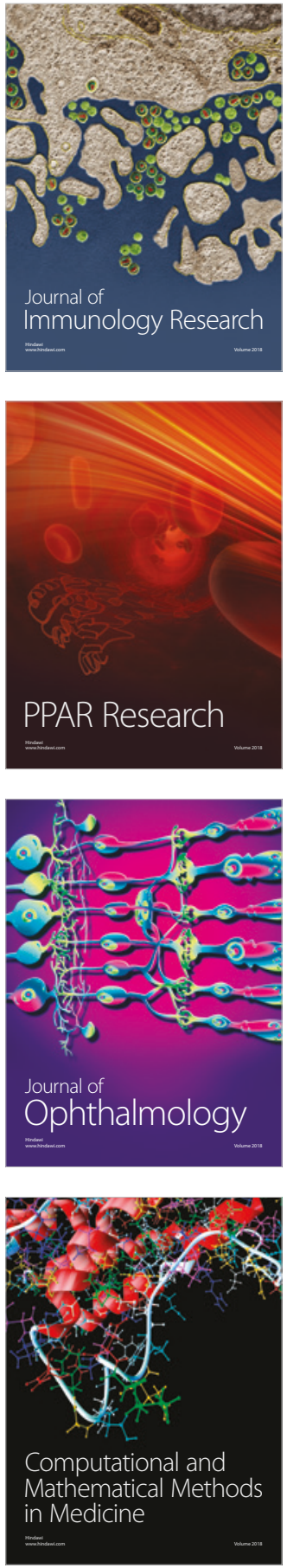

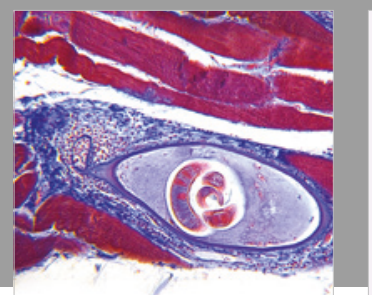

Gastroenterology Research and Practice

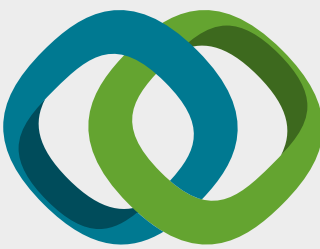

\section{Hindawi}

Submit your manuscripts at

www.hindawi.com
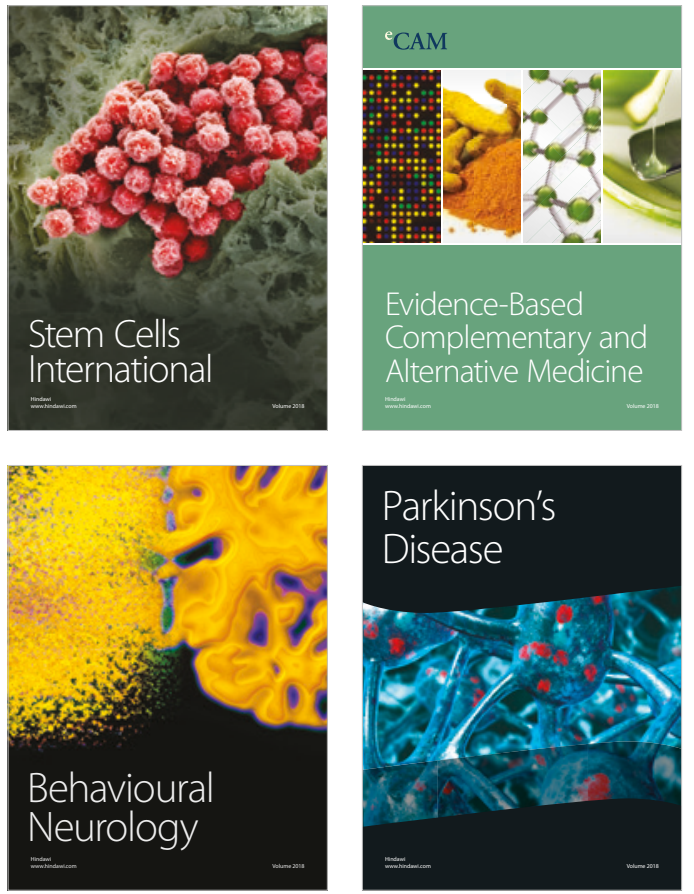

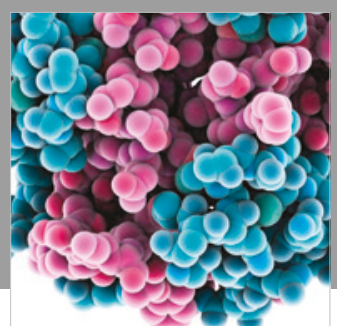

ournal of

Diabetes Research

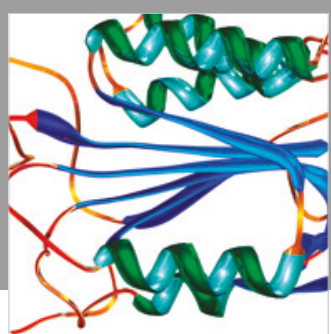

Disease Markers
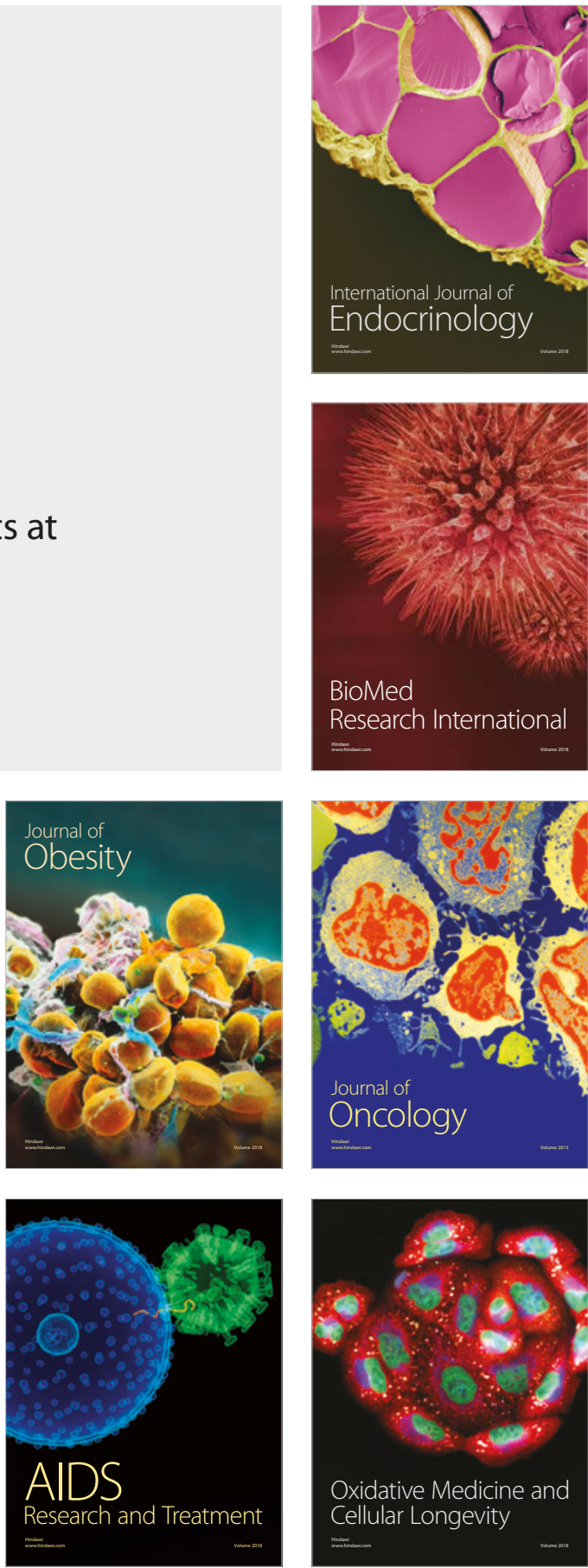